Revista de Derecho

de la Pontificia Universidad Católica de Valparaíso

XXXII (Valparaíso, Chile, $1^{\text {er }}$ Semestre de 2009)

[pp. $363-406$ ]

\title{
ORALIDAD Y PRUEBA: COMPARACIÓN Y ANÁLISIS CRÍTICO DE LAS EXPERIENCIAS REFORMADORAS DEL PROCESO CIVIL EN ALEMANIA Y ESPAÑA*
}

["Hearing and Evidence: Comparation and Critical Exploration throught the Reform Experience of the Spanish and German Civil Procedure Reform”]

\author{
Álvaro Pérez-Ragone** \\ Diego Palomo Vélez ${ }^{* * *}$
}

Resumen

Este artículo aborda la oralidad en el proceso civil y su relación con la prueba, solo en una visión netamente procedimental. Y ello en la perspectiva de un sistema (el español) que en la gran reforma del proceso civil muy tardíamente incorpora la oralidad en contraste con el sistema alemán en casi un siglo de diferencia. En el contexto de los estudios

\section{Abstract}

This article approaches the hearing in the civil proceeding and its relation with the evidence. The subject is the prospect of a system (the Spanish) that in the great reform of the civil process incorporates very delayed the hearing in contrast to the German system in almost a century of difference. In the context of the preparatory studies of the civil pro-

* Este trabajo forma parte de dos proyectos Fondecyt: i) Proyecto regular $\mathrm{N}^{\circ}$ 1085321, titulado "La oralidad en el marco de los cambios que requiere el sistema procesal civil. Sus efectos en la reforma a la justicia civil chilena”, que tiene como director responsable al prof. Diego Palomo Vélez; y ii) Proyecto iniciación No 11070054, titulado "Estudio histórico, comparado y dogmático de las conductas no cooperativas de las partes en el proceso civil (rebeldía - contumacia - default) de cara a su reformulación para una nueva y eficiente Justicia civil chilena", cuyo director responsable es el prof. Álvaro Pérez-Ragone.

** Abogado (UNT/Argentina); LL.M. y Doctor Iur. (Universidad de Colonia, Alemania); profesor asociado de Derecho Procesal Civil en la Facultad de Derecho de la Pontificia Universidad Católica de Valparaíso, Chile. Dirección Postal: Avenida Brasil 2950, Valparaíso, Chile. Correo electrónico: alvaro.perez@ucv.cl

*** Doctor en Derecho por Universidad Complutense de Madrid, España; profesor asociado de Derecho Procesal en la Facultad de Derecho de la Universidad de Talca, Chile. 
preparatorios de la reforma procesal civil, se busca poner a disposición del medio un estudio que se haga cargo de estos dos temas, puestos en relación, de manera de ilustrar respecto de las marcas que la oralidad pudiera o debiera dejar como nueva apuesta formal en sede procesal civil. Resulta especialmente relevante detenerse en esta relación, toda vez que el proceso civil ha ido evolucionando en el derecho comparado, lo que exige conocer y comprender el derrotero de los cambios y reformas que se han venido produciendo.

Palabras Clave: Oralidad - Proceso civil - Prueba. cedural reform in Chile, one looks for to put at the disposal of means a study that becomes position of these two subjects, positions in relation, of way to illustrate with respect to the marks that the hearing in the proceeding could or had leave as new formal bet in soothes procedural civilian. It turns out especially excellent to pause in this relation, every time the civil process has been evolving in the comparative civil procedure, which demands to know and to include/understand the map course of the changes and reforms that have come producing.

Key Words. Hearing - Civil Procedure - Evidence.

\section{INTRODUCCIÓN}

En las líneas que siguen se abordan dos de los temas que mayor interés han concitado por parte de la doctrina procesal durante el siglo pasado. Uno es la prueba y el otro la oralidad ${ }^{1}$. Demostración evidente de este interés son las diversas ponencias realizadas en el marco del Coloquio Internacional "Oralidad y escritura en un proceso civil eficiente" organizado por la Asociación Internacional de Derecho Procesal, en Gandia (España), bajo la coordinación del profesor Ortells, que permitió reunir una gran cantidad de participantes de las más variadas procedencias a hablar justamente de la oralidad (y sus marcas) en el proceso civil con la mirada puesta en la búsqueda de las fórmulas más provechosas de cara a la eficiencia del proceso $^{2}$.

${ }^{1}$ No se piense en las líneas que siguen como una manifestación más de la expansión del mito de la oralidad. Estamos convencidos que la apuesta por la oralidad en la Justicia civil no debe implicar desechar la utilidad y conveniencia de la escrituración de algunos actos del proceso. Lo que ocurre es que precisamente es en materia de prueba dónde la oralidad vienen a jugar un rol fundamental. En este tema nuestra legislación muestra un evidente retraso que debe enmendarse. Paradójicamente este retraso del modelo nacional puede resultar útil a la hora de reformarlo, ya que nos permite tener a la vista experiencias reformadoras que ya evidencian resultados. La experiencia nacional no es un punto en el tiempo y en el espacio aislado. Tiene su contexto histórico y comparado.

${ }^{2}$ Para una consulta de las ponencias realizadas en el Coloquio Internacional de la Asociación Internacional de Derecho Procesal "Oralidad y escritura en un proceso 
Cuando se habla de eficiencia no se piensa sólo en el tema de los (excesivos) tiempos de la respuesta jurisdiccional. El segundo gran problema que puede presentar la Justicia civil, también desde la perspectiva de la eficiencia, es que el fondo y la calidad de la decisión ${ }^{3}$ van perdiendo relevancia en el esquema formal que impone el sistema, que apareja, entre otras consecuencias, la virtual invisibilidad del juez durante todo el proceso. Esta pérdida de relevancia del fondo no puede ser de otro modo en un modelo en el cual quién debe decidir el conflicto suele no tener contacto directo con las partes ni con los medios de prueba que éstas aportan, reservando una eventual participación más activa sólo hacia el final a propósito de las medidas para mejor resolver utilizadas en algunos casos para salvar los papeles de la Justicia a última hora.

En el contexto de los estudios preparatorios de la reforma procesal civil ${ }^{4}$, se busca poner a disposición del medio un estudio que se haga cargo de estos dos temas, puestos en relación, de manera de ilustrar respecto de las marcas que la oralidad pudiera o debiera dejar como nueva apuesta formal. Resulta especialmente relevante detenerse en esta relación toda vez que el proceso civil ha ido evolucionando en el derecho comparado, lo que exige conocer y comprender el derrotero de los cambios y reformas que se han

civil eficiente", llevado a efecto en Gandia (España) entre los días 6, 7 y 8 de noviembre del 2008, véase: http://www.uv.es/coloquio/coloquio/Ponenc.htm.

${ }^{3}$ Taruffo, M., Oralidad y escritura como factores de eficiencia en el proceso civil, ponencia presentada en el coloquio referido en la nota anterior. Disponible en: http://www.uv.es/coloquio/coloquio/Ponenc.htm.

${ }^{4}$ Para introducirse en el tema de la reforma procesal civil chilena, véase: Bases para la reforma, en Revista de Derecho Procesal de la Universidad de Chile 20 (2005), pp. 437 ss.; Anteproyecto de nuevo CPC., en Revista de Derecho Procesal de la Universidad de Chile 21 (2008), pp. 25 ss.; también en Revista Estudios de la Justicia 8 (2006), pp. 41 ss. Se trata de un anteproyecto redactado por una comisión designada por el Foro. El documento se viene estudiando y analizando en el seno del propio Foro, y en el marco de los distintos seminarios organizados por varias universidades que se han comprometido con el proceso de difusión y análisis de los desafíos de la reforma procesal civil (entre ellas, destacadamente la Pontificia Universidad Católica de Valparaíso y la Universidad de Talca). Este anteproyecto, huelga decirlo, es demostrativo de que a estas alturas se impone ostensiblemente la necesidad de materializar un nuevo sistema procesal civil, lo que a su turno ha implicado asumir que no alcanza con la reforma parcial del actual centenario Código. Aunque es evidente, mejor advertirlo, este texto no puede entenderse como un producto final. Sostener esto sería alterar su propia naturaleza y, además, denotaría una falta de estudio del mismo, ya que a poco avanzar en su lectura evidencia una serie de omisiones, problemas y contradicciones que reflejan que aún existe importante tarea por realizar (importantes definiciones que tomar), en dónde este texto sólo constituye un punto de partida, la primera piedra de la cual debiera surgir la mejor articulación de una reforma. 
venido produciendo. Nuestro legislador debe estar informado del rumbo seguido por otros procesos de reforma. Este artículo no solo persigue una meta meramente descriptiva, sino y además constatar el trasfondo de las reformas hacia la oralidad en dos sistemas procesales antańo diferentes (justamente la oralidad era un punto donde se podía sustentar este juicio), pero contemporáneamente similares. Es cierto que coinciden en las razones y en la forma en la cual se concreta la oralidad, sin embargo desarrollar tópicos de ambos procesos civiles en torno a la oralidad, permite analizar visiones sobre su rol en relación a otros valores y en especial a la dinámica probatoria.

Con este señalado propósito efectuamos este análisis atendiendo a lo que han sido dos recientes experiencias de reforma, la alemana y la española, que primero dan perfecta cuenta de la estrecha relación entre la opción por el predominio de la oralidad y la actividad probatoria, y luego, muestran distintos caminos que existen en la concreción de esta relación ${ }^{5}$. Cuatro secciones componen este trabajo. En una primera (II) se desarrollan los antecedentes históricos inmediatos, por cierto contemporáneos sin mayores ambiciones, que llevaron a adoptar la oralidad en ambos sistemas. Una segunda sección (III) analiza el desarrollo del "proceso por audiencias", designación que nos permite tratar la oralidad sistemáticamente y no como un elemento o principio aislado. La relación entre la prueba y la oralidad manifestada en el rol de los sujetos procesales es el objeto de estudio en una tercera sección (IV). Finalmente se esbozan las principales conclusiones comparativas, descriptivas y críticas.

\section{ANTECEDENTES DE LA INTRODUCCIÓN DE LA ORALIDAD EN ALEMANIA Y ESPAÑA}

\section{Antecedentes de la "Zivilprozeßordnung" alemana.}

Desde el primer tercio del siglo XIX comienza la discusión en Alemania sobre la introducción de la oralidad. Como copia del modelo francés, es decir con escritos preparatorios y audiencia oral se proyecta el ordenamiento procesal civil ${ }^{6}$. Las ventajas del proceso oral predominaron

\footnotetext{
${ }^{5}$ Respecto al proceso civil alemán, en Chile, véase: Pérez Ragone, A. - Ortiz Pradillo, J. C., Código Procesal Civil alemán (ZPO.) (traducción con un estudio introductorio al proceso civil alemán contemporáneo, Montevideo, Fundación Konrad Adenauer, Programa Estado de Derecho para Sudamérica, 2006). Respecto del nuevo modelo español, véase: Palomo VÉlez, D., Oralidad en el proceso civil. El nuevo modelo procesal civil español (Santiago, 2008).

${ }^{6}$ Esto pretendía dejar atrás la excesiva escrituración italiano-canónica conservada desde el período de nueva recepción medieval y al inicio de la edad moderna. Para un estudio interdisciplinario del surgimiento y afianzamiento de la escrituración duran-
} 
sobre el proceso escrito en las consideraciones para su incorporación en el Código de $1877^{7}$.

La oralidad fue considerada central no solo desde el punto de vista externo del proceso para su celeridad y transparencia, sino además desde lo interno para el logro más coherente de la incorporación y apreciación de la prueba para el logro de una sentencia lo más legitimada posible. El juez debía apreciar y valorar la prueba según los cánones de la libre apreciación. No en vano se consideró de absoluta relevancia como marco de la libre valoración de la prueba -o la evolución de la prueba legal o tasada a la apreciación y ponderación sin restricciones innecesarias impuestas por el legislador- el dinámico y dramático transcurrir "dramático" que se manifiesta en un proceso oral. Dado que el proceso se debía reorientar al máximo acercamiento a la verdad sobre la cual se debía sustentar el convencimiento del juez, el que a su vez se debía manifestar en la sentencia, la oralidad servía mejor para los fines probatorios individuales de las partes y del tribunal, generales para la publicidad de lo acontecido, probado, no probado y finalmente reflejado en una resolución ${ }^{8}$.

La reforma de simplificación del proceso del año 1976 reforzó aun más el funcionamiento del proceso oral ${ }^{9}$. La oralidad cruza transversalmente

te la Edad Media puede verse: Lepsius, S. - Wetzstein, T., Als die Welt in die Akten kam Prozeßschriftgut im europäischen Mittelalter Rechtsprechung (Frankfurt am Main, 2008), VIII, passim. Muchos mitos y argumentos en pro y en contra de la escrituración o de la oralidad se afianzaron hacia la primera durante la Edad Media. Véase: Baur, F., Wege Zu Einer Konzentration der mündliche Verhandlung (Berlin, 1966), passim; Rosenberg, L. - Schwab, K. - OtTwald, P., Zivilprozessrecht (München, 2004), \$ 80, I; Murray, P. - Stürner, R., German Civil Justice (North Carolina, Durham, 2004), pp. 24-26.

${ }^{7}$ Sobre los principios procesales y su rol en general puede verse: SchnellenbaсH, H., Grundsätze des gerichtlichen Verfahrens, en Juristische Arbeitsblätter (1995), p. 785; para la oralidad en particular Kip, H.G.- von Hippel, F., Das sogenannte Mündlichkeitsprinzip (Köln, 1952), pp. 5-30; RosenberG - Schwab - GotTwald, cit. (n. 6), $\$ 80$, III.

${ }^{8}$ WaCH, A., Grundfragen und Reform des Zivilprozesses (Berlin 1914), pp. 5-24. Sobre el significado de la oralidad en la instauración del proceso civil liberal en Alemania centrado en el rol de A. Wach, véase: Dagmar, U., Adolf Wach (1843-1926) und das liberale Zivilprozessrecht (Berlin 2005), pp. 10-35. Véase, también, el detalle histórico y transfondo ideológico que significó para la libre valoración de la prueba reconstruir el proceso pasando de la escrituración a la oralidad Walter, G., Freie Beweiswürdigung (Tübingen, 1979), pp. 331 s.

${ }^{9}$ Bender, R., Das konzentrierte Verfahren mit dem Haupttermin (Stuttgarter Modell), en Bender, R. y otros, Das Verfahren nach der Vereinfachungsnovelle und vor dem Familiengericht (München, 1977), pp. 2-25. 
el proceso contencioso para el dictado de la sentencia en directa relación con la inmediación y la publicidad ${ }^{10}$.

No puede decirse que la "Ordenanza Procesal Civil" alemana (Zivilpro$z e$ ßordnung = ZPO.) regule un proceso plenamente escrito u oral, sino más bien de acuerdo al caso y al procedimiento, combina ambas alternativas ${ }^{11}$. La oralidad y el principio de escrituración moldean la dinámica externa del proceso, para determinar la comunicación de los sujetos procesales tiene directa vinculación con el derecho fundamental de tutela jurisdiccional y el derecho de audiencia o a ser oído (artículo 103 párr. $1^{\circ}$ Ley Fundamental) ${ }^{12}$. Dentro de la ZPO. ${ }^{13}$, la audiencia oral es el instrumento más importante para garantizar el derecho a ser oído aun cuando ello también pueda ser alcanzado por la escrituración.

La publicidad procesal es impracticable en un procedimiento escrito. Es de recordar, que la imposición del artículo 6 parte $1^{\text {a }}$ de la Carta europea de derechos humanos señala que todos los hombres tienen derecho a que sus causas sean conocidas en una audiencia pública ${ }^{14}$. Mucho más aún la aplicación de este principio tiene un significado de practicidad para el logro eficiente del diálogo procesal: los interrogatorios y contrainterrogatorios, la exposición de argumentos, el control de la actuación del tribunal como de las partes se efectúa en forma inmediata y viviente. Permite un mejor

\footnotetext{
${ }^{10}$ Gottwald, P., Simplified Civil Procedure in West Germany, en TheAmerican Joumal ofComparative Law 31 (Autumn, 1983) 4, pp. 687-701; LangbeIn, J., The German Advantage in Civil Procedure, en Chicago University Law Review 52, p. 823

${ }^{11}$ Kip, H. G., cit. (n. 7).

${ }^{12}$ El artículo 103 Abs. 1 GG. otorga a las partes de un proceso el derecho a manifestarse en forma completa y plena antes indicado de una resolución, esto se vincula con la garantía del derecho de audiencia (BVerfGE. 11, pp. 218, 220; 14, pp. 320, $323 ; 18$, pp. 380,$383 ; 22$, pp. 267,273$)$ que contiene el deber del tribunal de escuchar y contemplar las peticiones de los intervinientes para fundamentar su decisión (comp. BVerfGE. 50, pp. 32, 35; 65, pp. 305, 307 y BVerfG., 2 BvR. 779/04 del 19.10.2004, n. $(1-40)$.

${ }^{13}$ Pese a que se usa el género femenino para hacer referencia a la "Zivilprozessordnung" (= "Ordenanza Procesal Civil"), una traducción no literal de la palabra de género femenino "Ordnung", es "Código". Las transcripciones de parágrafos traducidas al español se extrajeron de Pérez Ragone, Álvaro - Ortiz Pradillo, Juan Carlos, cit. (n. 5).

${ }^{14}$ Schwab, K. - Gottwald, P., Verfassung und Zivilprozeß (Bielefeld, 1984), pp. 2-15, 20-30; Benda, E. - Weber, A., Der Einfluß der Verfassung im Prozeßrecht, en Zeitschrift für Zivilprozeß96, pp. 285 ss.; con detalle de la doctrina no pacífica sobre el carácter en tanto principio constitucional de la oralidad, véase: LüKE, G. - WAX, P. (editores), Münchener Kommentar zur Zivilprozeßordnung (München, 2002), I, "Einleitung", No 229-230 (véase la edición de 2008 con una introducción de Rauscher).
} 
cumplimiento de los deberes judiciales de interrogación, de indicación y advertencia como el correlato de las cargas y deberes impuestos a los partícipes procesales sean partes o terceros para un logro adecuado del $\$ 139$ ZPO. Coadyuva a una mayor eficiencia preventiva y de ejercicio del deber de veracidad que tienen las partes y la necesidad del esclarecimiento de los hechos facilitando la búsqueda de la verdad adecuada para una debida fundamentación de la sentencia ${ }^{15}$. De esta forma es posible un completo detalle en relación a los hechos y a la controversia objeto del proceso cuando existe una audiencia oral pudiendo el tribunal ejercer en forma más eficiente la dirección no solo formal, sino también material del proceso ${ }^{16}$.

El principio de oralidad sumado a otros principios en especial al de inmediación y concentración tiene un gran número de ventajas comparativas para una eficiente tramitación procesal, como así también para un mayor sustento de la legitimidad y credibilidad que la sentencia ${ }^{17}$.

\section{Antecedentes de la Ley No 1/2000, de Enjuiciamiento Civil española.}

Desde el año 2000 (en rigor, desde el año 2001, por una vacatio de un año), España cuenta con una legislación procesal civil renovada que logra dejar atrás el modelo de la Ley de enjuiciamiento civil (= LEC.) de 1881. El deficiente desempeño de la Justicia civil evidenció la necesidad de materializar cambios a través de la aprobación de una nueva ley. Uno de los más importantes cambios está dado por la introducción de mayores grados de oralidad en un modelo procesal civil que hasta ese momento y a pesar de todas las reformas parciales introducidas era excesivamente escrito.

Existía un importante grado de unanimidad para reconocer la existencia de serios problemas existentes bajo el modelo anterior a la LEC. actual que fueron afectando el desempeño de la Justicia civil la que, progresivamente, se fue distanciando de las necesidades de tutela de los justiciables. El diseño procesal basado fuertemente en la escritura era un problema. Concentrándonos en el juicio ordinario de mayor cuantía: excesiva rigidez formal, complejidad técnica, lentitud en su tramitación y elevado coste económico ${ }^{18}$.

${ }^{15}$ LüKE, G., cit. (n.14), I , No 231.

${ }^{16}$ Arens, P., Mündlichkeitsprinzip und Prozeßbeschleunigung im Zivilprozeß (Berlin, 1971), pp. 5-15; y la recensión de esta obra por Wolf, M., en Zeitschrift für Zivilprozeß 87, 98. 18; LüKE, G., cit. (n.14), I, No 232; LeIPOLD, D., Zivilprozeßrecht und Ideologie, en Juristenzeitung (1982), p. 441.

${ }^{17}$ LüKE, G, cit. (n.14), I , No 234.

${ }^{18}$ González García, J., Diversidad y diversificación de tipos procesales en el proceso civil español: Situación actual y perspectivas, en Díez-Picazo Giménez, I. - MartíneZ-Simancas y Sánchez, J. (coordinadores), Estudios sobre Derecho Procesal (Ma- 
Las explicaciones a tales características apuntaron a la medieval herencia procesal recibida por la LEC. de 1855 y por la LEC. de 1881, cual es, el solemnis ordo iudiciarius, recogido en las Siete Partidas. Esta particular herencia acarreó una serie de consecuencias en el diseño de los procesos declarativos ordinarios españoles, marcando decisivamente al juicio de mayor cuantía. La escrituración, la mediación, el tecnicismo y el formalismo excesivos adquirieren un papel absolutamente central.

Las reformas parciales no consiguieron mejorar la situación, fracasaron, quedando insatisfecha la búsqueda de una justicia realmente rápida y eficaz. Por ejemplo, la Ley No 34/84 de Reforma Urgente, considerada como la más importante reforma procesal realizada bajo el modelo hoy derogado, no logró una mejora real ya que no ofrecía una alternativa procesal decididamente diversa ${ }^{19}$. Además, en aquellos casos donde el legislador intentó mejorar la situación, la práctica forense se encargó de mantener el status quo. Ejemplo de ello fue lo ocurrido a propósito del juicio de menor cuantía y el establecimiento de la comparecencia previa, fase procesal introducida para reforzar la oralidad en las actuaciones procesales, pero que resultó ser víctima de un permanente simulacro por parte de los operadores. Lo propio respecto de la oralidad contemplada para el juicio verbal, de lege data, un proceso oral en el que según la ley regían la oralidad, la concentración y la inmediación judicial, pero en el que, por las resistencias de la práctica, llegó a ser un juicio más escrito que los demás procesos ordinarios.

La exageración de la escritura y sus consecuencias formales se reconoce como uno de los factores más influyentes en los problemas de la Justicia civil. El modelo procesal civil recogido en la LEC. de 1881, aún tras las reformas parciales, estuvo marcado por una profunda escrituración, dispersión procesal y mediación, especialmente dańino en lo que liga con la relación entre el juez y las pruebas ${ }^{20}$. Y ello, no obstante que la propia Ley

drid, Central Hispano, 1996), pp. 493 ss.

${ }^{19}$ Lo advertía Fernández-Ballesteros López: "Las modificaciones introducidas en la regulación del juicio de menor cuantía por la Ley 34/84 de Reforma Urgente no han servido para convertirlo en un proceso civil de corte moderno y más congruente con algunos preceptos constitucionales. Pero sí han alterado su sistema más gravemente de lo que el propio Legislador se propuso y sirve más para confundir que para aclarar nuestro ya bien oscuro sistema procesal. Por grande que sea el deseo del Legislador de convertir al juicio de menor cuantía en prototípico, el juicio ordinario tipo en nuestro Derecho sigue siendo el de mayor cuantía; tan es así que el primer precepto de los que regulan el nuevo juicio de menor cuantía comienza remitiéndose en bloque a las reglas del mayor cuantía”, en De la Oliva Santos, A. - FernándezBallesteros López, M. A., Derecho procesal civil (Madrid, Centro de Estudios Ramón Areces, 1997), II, p. 478.

${ }^{20}$ Por todos: Montero Aroca, Juan, Juicio critico de la LEC.: Conmemoración 
disponía que las pruebas (testimonial, confesional y pericial) se debieran practicar ante el juez, dotándole de facultades para intervenir en ellas, lo que sin embargo no pasó de constituir una norma sin aplicación real. Existía en los operadores una "cultura de la escritura" que logró, como dijimos, que se desvirtuara la oralidad en los casos en que la Ley expresamente la previó.

Ante este deficiente escenario, y atendida la mayor complejidad de los conflictos actuales, el nuevo modelo se hace cargo, con seriedad, racionalidad y prudencia, de estos arraigados problemas de funcionamiento que manifestaba la Justicia civil. La nueva ley se alinea con las tendencias de reforma universalmente consideradas más razonables y con las experiencias de más éxito real en la consecución de una tutela judicial que se demore sólo lo justo, es decir, lo necesario para la insoslayable confrontación procesal, con las actuaciones precisas para preparar la sentencia, garantizando su acierto. Se han desechado las fórmulas simplistas de reforma, inspiradas en unos pocos elementos entendidos como verdaderas panaceas. Además, la ley diseña los procesos declarativos de modo que la inmediación, la publicidad y la oralidad hayan de ser efectivas. Se piensa en un modelo practicable y no en un paraíso académico que no puede llegar nunca a tener aplicación efectiva.

La concreta regulación de la ley, se ha destacado, no deja espacio a concepciones ingenuas o maniqueas ${ }^{21}$ que entienden la forma escrita como la causa de todos los males del proceso civil y a la forma oral como el remedio mágico a todos esos problemas. La LEC., sin caer en desbordamientos, plantea una introducción de la oralidad con razonabilidad y prudencia, sin excesos que la tornen imposible y, por tanto, inútil.

\section{EL MARCO GENERAL DEL MODELO DE PROCESO CIVIL POR AUDIENCIAS}

\section{El marco de la oralidad, la publicidad y la inmediación en el proceso} civil alemán

El Tribunal Federal alemán estableció que el sentido y el objetivo del principio de la oralidad es obtener una impresión viva e inmediata del material controvertido a través de un procedimiento estructurado para

no festiva de un centenario, en Ramos Méndez, F. (director), Para un proceso civil eficaz (Bellaterra, Barcelona, Servicio de Publicaciones de la Universidad Autónoma de Barcelona, 1982), p. 213.

${ }^{21}$ Véase De la Oliva Santos, A. - Díez-Picazo Giménez, I. - Vegas Torres, J., Derecho procesal. Introducción (2a edición, Madrid, Centro de Estudios Ramón Areces, 2003), p. 77. 
lograr el intercambio de palabras de las partes, un inmediato esclarecimiento y el incentivo de preguntas e indicaciones del tribuna ${ }^{22}$. Solo así puede lograrse al máximo un marco para una adecuada resolución de la controversia. La oralidad implica un necesario contacto entre el tribunal que debe decidir, las peticiones y el material fáctico que aporten los sujetos intervinientes en el proceso ${ }^{23}$. Ello se logra a través del principio de inmediación procesal que impone la identidad del tribunal que conoció y presenció la discusión de prueba de las partes, con el tribunal que decide pronunciando la sentencia definitiva. La discusión y argumentos de convencimiento probatorios deben ser comprensibles para las partes y terceros ${ }^{24}$. Ello es mejor garantizado por la audiencia oral.

Como puede verse, es troncal la relación oralidad-publicidad-inmediación.

a) Oralidad. La audiencia oral obligatoria es la regla para los actos procesales en un proceso contencioso. La noción de "audiencia oral" puede ser amplia o restringida. En sentido amplio comprende tanto los actos de postulación y petición de las partes, la rendición de prueba como así también el pronunciamiento de la sentencia. En sentido restringido se podría reducir a la actividad de decisión ${ }^{25}$ ya que contemplando distintos supuestos, en puridad la audiencia oral requeriría sólo la actividad de una de las partes y del tribunal (el pronunciamiento de la sentencia) ${ }^{26}$. La audiencia oral es obligatoria cuando las partes tienen peticiones, alegaciones y pruebas para su fundamentación, necesitándose consecuentemente el diálogo con el tribunal para poder arribar a una decisión debidamente motivada ${ }^{27}$. Esa es la interpretación del $\$ 128$ I ZPO. en tanto es imperativa la oralidad en el procedimiento contradictorio para el pronunciamiento de una sentencia definitiva.

b) El significado de la audiencia oral. El principio de la obligatoriedad de la audiencia oral implica que solo puede decidirse previa

\footnotetext{
${ }^{22}$ Henckel, W., Die mündliche Verhandlung im Zivilprozeß aus kommunikationspsychologischer Sicht, en Zeitschrift für Zivilprozeß 110 (1997), pp. 91 ss.

${ }^{23}$ Murray, Stürner, cit. (n. 6), pp. 184-186.

${ }^{24}$ BGH Neue juristische Wochenschrift (1997), p. 398; y en otra sentencia de 1999 en la misma revista, p. 1339

${ }^{25}$ Rosenberg - Schwab - Gottwald, cit. (n. 6), $\$ 81$, I-II.

${ }^{26} \mathrm{El}$ principio de la oralidad rige para todas las audiencias: sean éstas de conciliación $(\$ 278)$, sea la primera audiencia preparatoria de la principal y obviamente audiencia principal de recepción de prueba y pronunciamiento de la sentencia. La oralidad se mantiene aún en el supuesto de allanamiento, renuncia o rebeldía de una de las partes. Véase Walsmann, G. K., Schriftlichkeit und Mündlichkeit, en Zeitschrift für Zivilprozeß 61, p. 381; Rosenberg - Schwab - Gottwald, cit. (n. 6), \$ 80, I.

${ }^{27}$ Rosenberg - Schwab - GotTwald, cit. (n. 6), $\$ 80$, II y III.
} 
audiencia oral y sobre lo conocido en ella ${ }^{28}$. La vulneración al principio de oralidad puede fundar la apelación, el recurso de revisión (casación) y el recurso por vulneración al derecho de audiencia ${ }^{29}$, siempre que no se haya renunciado a ello en audiencias orales posteriores $\$ 295 \mathrm{ZPO} .{ }^{30}$. Del $\$ 128^{31}$ surge que: a) ninguna resolución puede pronunciarse sin previa audiencia oral, siendo ello aplicable a los casos donde deban dictarse sentencias definitivas y resoluciones impulsivas del proceso, las excepciones deben determinarse en forma expresa; b) sólo aquello que fue objeto de la audiencia oral puede servir de fundamentación para la resolución que se pronuncie. Las peticiones probatorias y las alegaciones de las partes efectuadas en audiencia oral deben ser consideradas aceptándolas o rechazándolas en la sentencia definitiva.

C) Principios que rigen la audiencia oral. La audiencia oral en su funcionamiento se rige por cuatro principios: la unidad, la eventualidad, la equivalencia y la concentración. El principio de unidad establece que cada parte puede hacer valer sus peticiones de acción, defensa, medios de prueba y excepciones hasta el cierre de la última sesión de la audiencia oral. Así se reconoce la posibilidad de alegaciones posteriores siempre que sean

${ }^{28}$ CHONG-Hu, O., Der Prozeßtoff der zweiten Intanz im Zivilprozess in der deutschen Gesetzgebungsgeschichte seit 1877 (Berlin, 2004), pp. 10-12.

${ }^{29}$ Cfr. Vollkommer, M., Zivilprozeßordnung (Zöller, R.) (Köln, 2007), \$\$ 321a.2-18.

${ }^{30}$ Rosenberg - Schwab - GotTwald, cit. (n. 6), $\$ 81$, III, 1.

${ }^{31}$ El $\$ 128$ establece: "Principio de oralidad; procedimiento escrito. 1) Las partes tramitan el proceso en forma oral en el tribunal que tiene en él conocimiento. 2) El tribunal puede pronunciar una resolución sin audiencia oral con consentimiento de las partes, el que puede no obstante ser revocado por modificaciones esenciales del estado procesal [...]. Una resolución sin audiencia oral es inadmisible cuando han transcurrido más de tres meses desde el momento en el cual fue dado el consentimiento de las partes para un proceso escrito. 3) Cuando haya que decidirse sobre las costas, la resolución podrá pronunciarse sin audiencia oral. 4) Las resoluciones del tribunal que no sean sentencias, pueden pronunciarse sin audiencia oral, en tanto y en cuanto no se establezca lo contrario". Para el comentario en detalle véase: Peter, E., Münchener Kommentar zur Zivilprozeßordnung, Aktualisierungsband ZPO-Reform (München, 2002), $\$ 128$, passim; en detalle el desarrollo del tema en la edición del volumen I del MünchKomm. Ver el desarrollo de Wagner, C. No cualquier imposibilidad que obste a que se lleve a cabo una audiencia oral puede sustentar que se alegue la vulneración al principio. En una resolución del BGH ("Beschluss des Senats für Notarsachen"), del 6 de octubre de 2008, en Notarzeitung 6 (2008), se rechazó la impugnación de una audiencia no realizada por motivos de viaje y estado de salud del impugnante, entendiendo que no era justificable en esas circunstancias diferir la audiencia. 
efectuadas antes de la clausura de la última audiencia ${ }^{32}$. Del principio de unidad resulta la máxima de la eventualidad: todo de una vez. Vinculado a ello existe un tercer principio, el de equivalencia de las audiencias. Es decir para el dictado de la sentencia definitiva se estará al estado de hecho y de derecho del material procesal aportado en la última sesión de la audiencia pudiéndose considerar sólo aquello que es relevante y que fue incorporado oportunamente en la audiencia ${ }^{33}$. Finalmente por el principio de concentración se impone el deber al tribunal, en lo posible, de arribar a la solución de una controversia mediante una completa audiencia preparatoria más una audiencia principal $(\$ 272 \mathrm{ZPO} \text {. })^{34}$. De esta forma el tribunal debe intentar arribar al mejor grado de madurez en el conocimiento de una causa para poder pronunciarse sobre la misma ${ }^{35}$.

d) Publicidad. La oralidad tiene una íntima vinculación con la publicidad, lo que se encuentra establecido en los $\$ 169$ ss. (Gerichtsverfassungsgesetzes = GVG., o "Ley orgánica de los tribunales") en concordancia con el artículo 6 de la Carta europea de derechos humanos. Ya en el siglo XIX como oposición a las actuaciones en secreto del gabinete de justicia el artículo 178 de la Constitución de 1849 ("Paulskirchenverfassung") establecía: "el proceso judicial debe ser público y oral”36. En relación al

${ }^{32}$ Así $\$ 137$ “Tramitación de la audiencia oral. 1) La audiencia oral será iniciada mediante la presentación de las peticiones de las partes. 2) Las exposiciones de las partes deben ser libremente pronunciadas; ellas pueden hacer una relación de la litis en sus cuestiones de hecho y de derecho. 3) Una remisión a un escrito judicial es admisible en tanto y en cuanto ninguna de las partes se oponga y el tribunal lo sostenga por adecuado. La lectura de escritos judiciales tiene solamente lugar cuando sea necesario referir a su contenido literal. 4) En los procesos con asistencia legal obligatoria se debe admitir el otorgamiento de la palabra tanto al abogado como a la parte." En detalle: Peter, E., cit. (n. 31) \$137, No 1-13. Véase igualmente: Walter, G., cit. (n. 8), pp. 25-27.

${ }^{33}$ Así, véase: BGH Neue juristische Wochenschrift (2002), p. 2.862.

${ }^{34} \$ 272$. "Determinación del procedimiento. (1) La litis debe ser resuelta por regla en una audiencia amplia preparatoria de la audiencia oral (audiencia principal). El presidente determina si se ha de fijar una fecha para una audiencia previa ( $\$ 275)$ o se realizará un procedimiento escrito ( $\$ 276)$. La audiencia de conciliación y la audiencia oral deben realizarse lo antes posible". Lüke, Münchener Kommentar, cit., $\$ 272$, No 1-28, en la edición 2008 del MünchKomm. Ver el desarrollo de Prütting , H. sobre el tema.

${ }^{35}$ Baur, F, cit. (n. 6), pp. 1-10; Walter, G., cit. (n. 8), p. 73.

${ }^{36}$ Hay excepciones en cuestiones de menores y en familia, para protección de la intimidad, secretos comerciales ( $\$ 170.171$ b, 172 GVG.). En ningún caso la publicidad se limita en relación a lo acontecido en la audiencia hasta el dictado de la sentencia ( $\$ 173$ GVG.). Este "principio de publicidad general” se diferencia de la "publicidad para las partes" que es mucho más amplia y comprende todos los actos 
derecho fundamental de libertad de prensa e información no se afecta por las disposiciones que restrinjan el uso de registro y transmisión ${ }^{37}$. La relación libertad de prensa y publicidad del proceso se regula en el $\$ 169$ 1 GVG. ${ }^{38}$. La modalidad a través de la cual se efectúa la comunicación de los medios de prensa audiovisuales sobre determinada etapa del proceso puede ser regulada por el legislador. De esta forma las audiencias de acuerdo al $\$ 1692$ GVG. no pueden grabarse ni retransmitirse por los medios de prensa, habiendo sido esto declarado constitucional como limitación a un derecho fundamental ${ }^{39}$. De esta forma se establece el principio fundamental de la publicidad de la sala de audiencias desde el inicio hasta la conclusión de las mismas ${ }^{40}$.

e) Inmediación. La inmediación impone que la audiencia oral se lleve a cabo por ante el tribunal que conoce, pudiendo solamente participar en el pronunciamiento de la sentencia el juez que participó en aquella ( $\$$ 309). De esta forma la rendición de pruebas se realiza por ante el tribunal que conoce efectivizándose el principio de inmediación de la prueba $(\$$ 355 parte 1$)^{41}$. Ello admite ciertas excepciones en los supuestos de los jueces exhortados en la cooperación jurisdiccional $(\$ 362)^{42}$. También

sin limitación que se realizarán en el proceso. Así el \$357 ZPO. dispone: "Publicidad para las partes. 1) A las partes les está permitido participar en el recibimiento a prueba”. 1.633.

${ }^{37}$ Según lo decidido por el BVerGE en Neue juristische Wochenschrift (2001), p.

${ }^{38}$ Comp. BVerfGE 103, pp. 44, 61. El control público de los actos procesales se garantiza por la sola presencia de los medios de prensa y su posibilidad de informar (comp. BGH, providencia del 10 de enero 2006 - 1 StR 527/05, en Neue juristische Wochenschrift (2006), pp. 1220, 1221).

${ }^{39}$ Comp. BVerfGE 103, p. 66.

${ }^{40}$ Comp. Para el proceso penal BGHSt 23, p. 123. No existe tal limitación sobre lo que acontezca antes de iniciada o luego de concluida la audiencia (comp. BGHSt 23 , pp. 123, 125). De esta forma se garantiza en cierta medida la protección de los derechos de la personalidad de los intervinientes en el proceso (Comp. BVerfGE 103, pp. 44, 68). Ver igualmente BVerfG, 1 BvR 620/07 del 19.12.2007, No (1 62).

${ }^{41}$ Así el $\$ 355$ : “Inmediatez en la recepción de la prueba. 1) El recibimiento a prueba tiene lugar en el tribunal del proceso. Solo puede realizarse por ante alguno de los miembros del tribunal o transferirse a otro tribunal en los casos que esta ley determina".

${ }^{42} \$ 362$ : "Recepción de prueba por juez delegado. 1) Caso de que la recepción de prueba deba realizarse por otro tribunal, el presidente del tribunal emite el requerimiento de encargo. 2) El juez envía las audiencias descriptas para la recepción de prueba en original a la secretaría del tribunal; la secretaría se encarga de informar a las partes sobre la recepción del requerimiento de encargo". 
en determinados casos cuando se delega a un juez -que es miembro del tribunal que conoce- la realización de determinada actuación $(\$ 361)^{43}$. Las declaraciones de testigos en procesos penales pueden ser valoradas como prueba documental. En caso que se solicite su declaración, ésta se debe producir como prueba mediante la declaración de testigos en forma inmediata antes tribunal que conoce ${ }^{44}$.

f) La combinación procedimental escrita-oral: los escritos preparatorios y posteriores. La oralidad no excluye la posibilidad de actuaciones escritas de las partes y del tribunal. De esta forma, algunas actuaciones procesales pueden efectuarse solo en forma escrita, así por ejemplo lo establecido para el escrito de demanda (\$253 ZPO. $)^{45}$, la interposición de recursos y medios de impugnación y otros actos procesales. La lengua escrita u oral a emplearse es el alemán no siendo considerados aportes en lengua extranjera ${ }^{46}$. Existe el imperativo de un traductor o intérprete como requisito del debido y justo proceso ( $\$ 185$ p. 1, 1 GVG.) y artículo 1, 20 p. 3 GG. ${ }^{47}$ y por imposición del Tribunal Europeo de Derechos Humanos ${ }^{48}$.

Otras actuaciones procesales pueden efectuarse facultativamente en forma oral o escrita a través de determinados escritos o en audiencia oral, como ser la modificación de la demanda o la reconvención. Los actos procesales de las partes que impliquen peticiones que determinan el contenido y objeto de la decisión futura por su importancia deben efectuarse tanto escrita como oralmente (\$297): así en la audiencia oral se puede hacer referencia al escrito de demanda, muy frecuente en la práctica. Un cierto grado de procedimiento escrito se combina no sólo por los escritos propios de las partes, sino también por la confección del expediente ${ }^{49}$.

g) La preparación de la audiencia oral. La audiencia oral princi-

${ }^{43} \$ 361:$ "Recepción de prueba por el juez encargado. 1) En tanto la recepción de prueba deba realizarse por un miembro del tribunal, éste será designado en el momento de comunicación de la providencia probatoria por el presidente del tribunal, determinándose igualmente el plazo para la recepción de la prueba".

${ }^{44} \mathrm{BGH}$ Neue juristische Wochenschrift (1995), p. 2.857; BGH Neue juristische Wochenschrift (2000), p. 1.420.

${ }^{45}$ Rosenberg - Schwab - Gottwald, cit. (n.6), $\$ 81$, III, 2.

${ }^{46}$ BGH NJW Neue juristische Wochenschrift (198), p. 532.

${ }^{47}$ BVerfG en Juristenzeitung (1983), p. 659.

${ }^{48}$ Neue juristische Wochenschrift (1985), p. 1.273; BVerfGE 54, pp. 277, 291; BVerfGE 101, pp. 275, 294; BVerfGE 70, pp. 297, 308; 108, pp. 129, 137). BVerfG, 2 BvR 779/04 del 19.10.2004, No (1 - 40).

${ }^{49}$ Lange, M., Bezugnahme im Schriftsatz, en Neue juristische Wochenschrift (1989), p. 438 
pal puede prepararse en forma oral o escrita ${ }^{50}$, según lo ordene el tribunal por considerarlo necesario ${ }^{51}$. De acuerdo a la complejidad del proceso se puede disponer una audiencia preliminar o que ésta sea sustituida mediante escritos preparatorios o combinar ambas posibilidades ${ }^{52}$. El objetivo es lograr que en una audiencia principal se arribe a una sentencia que ponga fin al proceso. Así tienen su utilidad los escritos preparatorios que contienen las peticiones sustanciales de agresión y defensa de partes, la que -de acuerdo al $\$ 273^{53}$ ZPO.- deben contener todo el elemento necesario que sirva para la adecuada preparación de los puntos que serán tratados en la audiencia oral ${ }^{54}$. No es necesaria la introducción de referencias relativas a la prueba o al derecho aplicable, sin embargo tampoco está vedado. Los

\footnotetext{
${ }^{50}$ Se nota una tendencia a privilegiar la preparación por escrito en los sistemas europeos. Ejemplo de ello sería el Reglamento Europeo 861 de 2007 que establece un procedimiento para demandas transnacionales de escasa cuantía, en el que se regula un procedimiento simplificado basado en escritos. En efecto, se ha apuntado, cuando se trata de procesos complejos e importantes la tendencia general es emplear mecanismos procesales escritos. Con todo, excepción de esta tendencia sería el caso español, donde la preparación oral de la audiencia de juicio en la audiencia previa funciona muy bien incluso en causas complejas e importantes. Véase: TARUfFo, M.,
} cit. (n.3).

${ }^{51} \$ 275$ : “Audiencia preliminar. 1) Para la disposición de la audiencia preliminar mediante la cual se preparará la principal, el presidente u otro miembro del tribunal por él determinado puede emplazar al demandado para la presentación de un escrito de contestación. En otro caso se debe exigir al demandado que presente en un escrito mediante abogado la mención de los medios de defensa que aportará sin demora, escrito que se debe comunicar al tribunal; $\$ 277$ parte 1 oración 2 rige en lo que corresponda. 2) En caso que el proceso no se clausure en la audiencia preliminar debe entonces el tribunal pronunciar todos los mandamientos que sean necesarios para la preparación de la audiencia principal oral." Véase al respecto: Prütting, H., Münchener Kommentar (2008), $₫ 275$, № 1-15.

${ }^{52}$ SтіскеLвrock, B., Inhalt und Grenzen richterlichen Ermessens im Zivilprozeß (Köln, 2002), pp. 560-566.

${ }^{53} \$ 273$ : "Preparación de la audiencia. (1) El tribunal tiene que proveer las medidas preparatorias necesarias en forma oportuna”. Por su lado el $\$ 276$ establece para el procedimiento escrito: "(1) En caso que el presidente no determine ninguna audiencia preliminar a la principal exige entonces al demandado con la notificación de la demanda que, si desea defenderse debe presentar su contestación por escrito ante el tribunal en un plazo perentorio de dos semanas luego de la notificación de la demanda; de este requerimiento debe hacerse saber al demandado". Véase en detalle: PrütTING, Münchener Kommentar, cit. (n. 51) \$ 273, No 1-16.

${ }^{54}$ Así lo dispone el $\$ 129$ : “Escritos preparatorios. (1) En el proceso con asistencia letrada obligatoria, la audiencia oral será preparada por presentaciones escritas. (2) En otros procesos, las partes pueden mediante orden judicial preparar la audiencia oral mediante escritos o bien por declaraciones en el protocolo en la secretaría del tribunal.” En detalle Wagner, C., Münchener Kommentar, cit., $\$ 129$, № 1-17. 
escritos se presentan en copia y son notificados de oficio ${ }^{55}$. El tribunal igualmente puede ordenar que se presenten determinados escritos en un plazo determinado para la preparación de la audiencia oral. La no presentación en tiempo implica la preclusión de presentaciones posteriores de acuerdo al $\$ 296$ ZPO. ${ }^{56}$. Luego de concluida la audiencia oral no pueden incorporarse nuevos escritos por la regla de preclusión. Las excepciones están establecidas en $\$ 283$, en tantos los escritos incorporados con posterioridad tengan relación y relevancia con lo transcurrido en audiencias anteriores. La consideración de escritos presentados con posterioridad para su aceptación o rechazo queda reservada a la ponderación discrecional del tribunal ${ }^{57}$. En el supuesto que no se verifiquen los casos autorizados para presentar escritos con posterioridad a la clausura de la audiencia oral no existe posibilidad de hacerlo ${ }^{58}$.

h) Las excepciones a la oralidad. En primer lugar no es necesaria sino facultativa en un procedimiento que concluya en el dictado de una sentencia interlocutoria. En segundo lugar en los principales casos establecidos: i) \$253: interposición de la demanda; ii) $\$ 340$ : oposición contra sentencia en rebeldía; iii) ) $\$ \$ 519,520,549,551$, 554: interposición de recursos; iv) ) Para el pronunciamiento de una sentencia en rebeldía o en caso de allanamiento en un procedimiento escrito $\left(\$ \$ 307^{59}, 331 \mathrm{No}\right.$ $\left.3^{60}\right)$; v) $\$ 1282$ ) cuando las partes de común acuerdo soliciten el procedimiento escrito; vi) $\$ 128$ No 2) en caso de resoluciones sobre costas; vii)

${ }^{55}$ La debida preparación para las audiencias orales definen en gran medida el éxito o fracaso de la de oralidad, lo que también se puede verificar en la práctica procesal civil alemán Hendel, D., Wider den Niedergang der Kultur der mündlichen Verhandlung im Zivilprozeß, en Deutsche Richterzeitung (1992), pp. 91 ss.

${ }^{56}$ Walchshöfer, A., Berücksichtigung Nachgereichter Schriftssätze im Zivilpro$z e ß$, en Neue juristische Wochenschrift (1972), p. 1028.

${ }^{57}$ Según la redacción del $\$ 356$. "Plazo de presentación de la prueba. En caso de un impedimento contra el recibimiento a prueba que sea de duración indeterminada, debe fijarse por providencia un plazo por el cual, luego de su vencimiento infructuoso, el medio de prueba solo puede ser usado cuando, según el libre convencimiento del tribunal, por ello no se demore el proceso".

${ }^{58}$ Un tratamiento general sobre el tema en: WETH, S., Die Zurückweisung verspäteten Vorbringens im Zivilprozeß (Köln, 1988), passim, esp. pp. 150-200. Igualmente Stickelbrock, Inhalt, cit.(n. 52), p. 513. Sobre la preclusión en general Отто, Н., Die Präklusion. Ein Beitrag zum Prozeßrecht (Hamburgo, 1969), pp. 10-35.

${ }^{59}$ Dispone el $\$ 307$ : “Reconoce una parte la pretensión hecha valer por la otra en forma total o parcial, debe entonces pronunciarse conforme a dicho reconocimiento. No es necesaria una audiencia oral".

${ }^{60}$ Dispone: “(3) En caso que el demandado no se haya manifestado oportunamente contra el $\$ 276$ parte 1 oración 1 y parte 2 y quiera defenderse contra la demanda, el tribunal se pronuncia a petición del actor sin audiencia oral". 
en el procedimiento establecido en el $\$ 495$ a, donde la oralidad es sólo obligatoria a petición de parte; y viii) en los casos en los cuales se pueda decidir de acuerdo al estado del expediente (\$\$251 $\mathrm{a}^{61}, 331 \mathrm{a}^{62}$ y cuando pueda considerarse a los efectos de la fundamentación de la sentencia los escritos presentados por las partes con posterioridad a la clausura de la audiencia oral ${ }^{63}$.

i) Escrituración con oralidad a pedido de parte en procesos de menor cuantía. En las causas de menor cuantía existe una flexibilidad procedimental que parte de la regla de la escrituración. De esta forma el juzgado de circuito puede determinar el procedimiento, de acuerdo con su discrecionalidad equitativa, cuando el monto de la causa no sea superior a 600 euros, debiendo tramitarla oralmente solo a petición de parte ${ }^{64}$.

\section{La oralidad y la escritura en la nueva normativa española.}

La oralidad tiene formulación en España a nivel constitucional. Prescribe el artículo 120.2 de la Constitución española: "El procedimiento será predominantemente oral, sobre todo en materia criminal". Por ello, el proceso civil debía reformarse en el sentido marcado por la norma consti-

${ }^{61} \$ 251$ a: "Rebeldía de ambas partes; resolución según el estado del expediente. (1) En caso que no comparezcan o no participen ambas partes en una audiencia, el tribunal puede decidir según el estado del expediente. (2) Una sentencia según el estado del expediente puede ser pronunciada solo cuando ya anteriormente se hizo una audiencia oral. La sentencia puede ser dictada como mínimo en dos semanas".

${ }^{62} \$ 331$ a: "Resolución de acuerdo al estado de la causa en el expediente. En caso de incomparecencia de una parte en término a la audiencia oral, la contraparte puede solicitar una sentencia de acuerdo al estado del expediente en vez de una en rebeldía; esta petición debe ser admitida en tanto los hechos aparezcan suficientemente claros para dicha resolución. El $\$ 251$ a. parte 2 rige en lo que corresponda”.

${ }^{63}$ Hay que sumar a estos casos los siguientes: 9) \$\$ 924, 936: oposición contra embargo y medidas cautelares; 10) El procedimiento monitorio o el cautelar; 11) Igualmente no es obligatoria en relación a los actos a realizarse por ante el presidente de un tribunal, un juez exhortado o delegado como así también todos los actos que deban realizarse por ante el funcionario oficial documentador o secretario. En relación al proceso ejecutivo aun cuando rija la oralidad, funciona en forma escrita. Ver al respecto Stürner, R., Prinzipien der Einzelzwangsvollstreckung, en Zeitschrift für Zivilprozeß 99 (1986), pp. 291 ss.; Prüting, H. - Sтіскецвrock, B., Zwangsvollstreckungsrecht (Stuttgart, 2002), pp. 28-30.

${ }^{64} \$ 495$ a: "El juzgado puede determinar el procedimiento de acuerdo a su discrecionalidad equitativa cuando el monto de la causa no sea superior a 600 euros. A petición de parte debe tramitar en forma oral.” En detalle véase: Kunze, A., Das amtsgerichtliche Bagatellverfahren nach $\$ 495$ a ZPO (Bielefeld, 1995), passim; STICKelbrock, B., Inhalt, cit. (n. 52), pp. 622-656; Westerwelle, Mündlichkeitsgrundsatz, cit., pp. 58 ss.; ScHNEIDER, E., ZPO-Reform (München, 2001), No 48-49. 
tucional. La nueva normativa refuerza extraordinariamente la aplicación de la oralidad, con lo que el proceso civil se moderniza y se ajusta a la norma constitucional. El legislador fue consciente de la (mala) influencia del absoluto gobierno de la forma escrita en el deficitario desempeño de la Justicia civil. El diseńo procesal basado en la escritura se alzaba como un obstáculo para una reforma efectiva ${ }^{65}$.

Se acogen las ventajas de la oralidad e inmediación, tomando los resguardos necesarios con el propósito de que la práctica no pudiera dejarlas en la inaplicación, otra vez. Es la propia estructura y contenido de las distintas fases del proceso la encargada de garantizar la efectividad y real aplicación de estos mayores grados de oralidad.

a) La estructura de los procesos declarativos ordinarios. Se lee en la "Exposición de motivos": "La ley diseña los procesos declarativos de modo que la inmediación, la publicidad y la oralidad hayan de ser efectivas. En los juicios verbales, por la trascendencia de la vista; en el ordinario, porque tras la demanda y contestación, los hitos procedimentales más sobresalientes son la audiencia previa al juicio y el juicio mismo, ambos con la inexcusable presencia del juzgador" ${ }^{66}$.

b) Estructura del juicio ordinario. La estructura del juicio ordinario que recoge la LEC. combina oralidad y escritura. Sintéticamente, el juicio se inicia por un trámite de alegaciones escritas y se desarrolla en audiencias sucesivas orales, la audiencia previa y el juicio, donde se practica la prueba. Finaliza con una sentencia escrita, que se dicta una vez finalizada la audiencia de prueba.

Tanto la demanda como la contestación son escritas, siguen siendo escritas.

Tras estas alegaciones iniciales escritas, a las cuales se pueden agregar eventualmente otras (léase la declinatoria o la reconvención, que también son actuaciones escritas) el diseño contempla una primera audiencia destinada fundamentalmente a la preparación del juicio ${ }^{67}$. En esta audiencia previa, se intenta inicialmente un acuerdo o transacción de las partes que ponga fin al proceso y, si tal acuerdo no se logra, se resuelven las posibles

${ }^{65}$ Existió consenso en así denunciarlo. Para lograr un cambio real, se puntualizaba, era preciso no solamente reducir el número de procesos existentes, sino definir un tipo de proceso basado en los principios de concentración, oralidad e inmediación.

66 "Exposición de Motivos" de la LEC.

${ }^{67}$ Acertadamente se ha subrayado que la estructura del juicio ordinario huye tanto de la extremosidad de la oralidad absoluta como de una vista no suficientemente preparada. De la Oliva Santos, A., Sobre la Ley 1/2000, de 7 de enero, de Enjuiciamiento Civil: criterios inspiradores e innovaciones principales, en Revista de los Tribunales de Justicia 2 (2000), p. 131. 
cuestiones sobre presupuestos y óbices procesales, se determinan con precisión las pretensiones de las partes y el ámbito de la controversia, se intenta nuevamente un acuerdo entre los litigantes y, en caso de no alcanzarse y de existir hechos controvertidos, se proponen y admiten las pruebas pertinentes y útiles.

En la vista principal, la audiencia de juicio, se materializa la práctica de la prueba, con destacados grados de oralidad, inmediación y concentración. También se formulan las conclusiones sobre la práctica de la prueba, finalizando con informes sobre aspectos jurídicos. De todas las actuaciones públicas y orales quedará constancia mediante instrumentos aptos para la grabación y reproducción del sonido y de la imagen, sin perjuicio de lo que se registra en las actas. Tras ello, y sin perjuicio de la posibilidad de que se acuerden diligencias finales (que sustituyen a las diligencias para mejor proveer), se finaliza con la fase decisoria, donde la sentencia sigue siendo escrita.

c) Estructura del juicio verbal. Respecto al juicio verbal el modelo es más sencillo. Se inicia por una demanda escrita, sucinta ${ }^{68}$, con inmediata citación para la vista. En efecto, tras la demanda, y sin perjuicio de eventuales actuaciones que el demandado puede llevar a cabo antes del acto de la vista (declinatoria, reconvención u oposición de un crédito compensable) se convoca al juicio, la vista, en el que oral y concentradamente se lleva a efecto tanto la contestación de la demanda, el saneamiento de las cuestiones procesales, y la fijación definitiva de los hechos como la proposición y práctica de los medios de prueba. El acto de la vista se celebra inexcusablemente ante el juez de la causa. Una vez practicadas las pruebas se da por terminada la vista y procede la emisión del fallo, sin que sean admisibles las diligencias finales del juicio ordinario. Cabe destacar que se trata de un diseño procedimental más simple y acusadamente más oral y concentrado ${ }^{69}$.

${ }^{68}$ Incluso, en aquellos juicios verbales en donde se reclame una cantidad que no exceda de 900 euros la demanda podrá consistir en el simple llenado de unos impresos normalizados, a disposición de los actores en el Tribunal correspondiente. Aunque, también debe anotarse, nada impide que el actor presente una demanda ajustándola a las exigencias de la demanda en el juicio ordinario.

${ }^{69} \mathrm{Al}$ respecto conviene precisar que el Proyecto de la LEC. preveía dos modalidades de juicio verbal, una de ellas para los asuntos más simples o sencillos ya sea por su escasa cuantía o complejidad (en el cual tras la demanda escrita sucinta debía citarse a ambas partes al acto de la vista) y otra destinada para asuntos menos sencillos, bien por tener cuantía superior (aunque no de la envergadura de las cuantías propias del juicio ordinario) o tener una complejidad mayor, en donde después de la demanda escrita semejante a la prevista para el juicio ordinario, se preveía una eventual contestación también por escrito del demandado, para después dar paso a la vista oral. El 


\section{Las audiencias en el nuevo proceso civil español.}

a) La técnica de las audiencias. Se señala por la propia "Exposición de Motivos" que los hitos procedimentales más sobresalientes en el nuevo diseño procesal lo constituyen la vista en el juicio verbal, y la audiencia previa al juicio y el juicio mismo, en el juicio ordinario. De este modo, y sin perjuicio del relevante papel que mantiene la escritura dentro del nuevo sistema, es claro que el legislador español ha regulado procedimientos inspirados predominantemente en la oralidad. Para ello, en la LEC. se utiliza la técnica de las audiencias o vistas ${ }^{70}$ en las que queda

trámite parlamentario no dio luz verde a esta doble modalidad de juicio y optó por configurar como única modalidad de juicio verbal a aquella que más decididamente apostaba por la oralidad y la concentración. En efecto, la alternativa que se planteaba en el proyecto de LEC. hubiese permitido que en aquéllos casos no tan sencillos existiera la posibilidad de fijar antes de la audiencia las alegaciones y pretensiones de las partes. Al optarse por un único diseño más oral y concentrado (sin contestación por escrito) el juicio verbal espańol viene presentando un importante problema que se traduce justamente en la ausencia de una fijación con carácter previo a la vista de las alegaciones y pretensiones de ambas partes, lo que deriva en frecuentes suspensiones y aplazamientos. Y bien se sabe que el abuso en las suspensiones y los aplazamientos son un verdadero cáncer (uno de los peores enemigos) de los procesos que tienden hacia mayores grados de oralidad. Tanto así que la concentración procesal perseguida en esta clase de modelo procesal puede quedar en letra muerta. El profesor Gascón explica bien el problema a partir de la referencia a Espańa y Francia: "Debe ponerse de relieve la frecuencia con la que los legisladores nacionales incurren en un error de base: a la hora de diseñar modelos procedimentales, lo habitual es que las mayores dosis - y los excesos - en la oralidad se reserven para los procesos que tienen una menor cuantía. Esto es lo que sucede en España con el juicio verbal (hasta 3000 euros) o lo que ocurre en Francia con los procesos ante el tribunal "d'instance" y el "juge de proximité". Cuando los intereses económicos en juego son elevados, el legislador considera razonable que el proceso tenga un cierto soporte escrito, al menos en sus momentos iniciales; en cambio, los riesgos de una oralidad completa se asumen únicamente cuando el interés económico en juego es más reducido. Ahora bien, sobre todo en el ámbito civil y mercantil, es absolutamente incorrecto identificar la escasa cuantía de un litigio con una pretendida sencillez fáctica o con una eventual simplicidad de las cuestiones jurídicas que han de ser enjuiciadas en el proceso, elementos éstos - la sencillez fáctica o la simplicidad jurídica de un caso - que son los que, en puridad, justifican un cauce procesal más liviano, que puede traducirse en la previsión legal de un procedimiento total o casi totalmente oral”. Véase: GAscón, F., Un nuevo instrumento para la tutela de los consumidores y de los créditos transfronterizos: el proceso europeo de escasa cuantía. Revista Ius et Praxis 1 (2008), p. 56.

${ }^{70}$ Dice Picó I. Junoy, J., Los principios del nuevo proceso civil, en Alonso-Cuevillas Sayrol, J. (coord.), Instituciones del nuevo proceso civil. Comentarios sistemáticos a la Ley 1/2000 (Barcelona, Difusión Jurídica, 2000), p. 62: "La nueva LEC. ha optado con claridad por regular procedimientos inspirados por el principio de oralidad y sus principios- consecuencias: El de inmediación, el de concentración y el de 
patente la fuerza real y efectiva que han tomado las reglas procesales de la oralidad, concentración e inmediación judicial en la nueva normativa. Especialmente en lo que liga con la forma de practicarse la prueba que ahora debe ser en una vista pública, contradictoriamente, en presencia del juez, y bajo la forma oral.

b) Reglas sobre audiencias contenidas en la LEC. Ésta consagra una serie de reglas de carácter general tratándose de las vistas y audiencias contempladas en el nuevo proceso civil ${ }^{71}$. Entre ellas destacan las reglas sobre documentación, la publicidad, la inmediación, la concentración y las resoluciones orales.

c) Regla de la documentación. En primer lugar, el desarrollo de la vista se registrará en soporte apto para la grabación y reproducción del sonido y la imagen o, si no fuera posible, sólo del sonido. La grabación se efectuará bajo la fe del secretario judicial, a quien corresponderá la custodia de las cintas, discos o dispositivos en los que la grabación se hubiere efectuado. Las partes podrán solicitar a su costa una copia de estos soportes (deberán aportar el soporte en que deba efectuarse la grabación).

En seguida, si estos medios no pudieren utilizarse por cualquier causa, la vista se documentará por medio del acta completa realizada por el secretario. Debemos destacar que no se subordina el acta a la eventualidad de que los medios de grabación no se puedan utilizar. El acta procede siempre y en todo caso. Con todo, cuando la actuación oral sí haya sido registrada en soporte apto para la grabación y la reproducción, el acta que se levante se limitará a consignar, junto con los datos relativos al tiempo y al lugar, las peticiones y propuestas de las partes y las resoluciones que adopte el Tribunal, así como las incidencias que no pudieran constar en aquellos soportes por no poder grabarse (será un acta acotada en su contenido);

En fin, cuando el Tribunal lo considera oportuno y conveniente puede unirse a los autos, en el plazo más breve posible, transcripción escrita de lo que hubiera quedado registrado en los soportes correspondientes.

publicidad. Para ello, formula una regulación de los procedimientos utilizando la técnica de las audiencias, en las que se materializa dicha oralidad".

${ }^{71}$ En la doctrina procesal no existe completo acuerdo en torno a la audiencia previa al juicio. Somos del parecer que estas reglas deben ser aplicables también a esta importante audiencia, pues refuerzan los propósitos del legislador con relación a que este acto procesal complejo no se falsee - otra vez - por la práctica judicial y forense. $\mathrm{Ni}$ qué decir respecto de las ventajas de la publicidad, la que no sería necesaria si no se le considera como vista. Lo propio respecto a las ventajas de la grabación de la misma: Si no se le considera comparecencia (artículo 147), su documentación sólo se efectuaría mediante acta. 


\section{Publicidad de las vistas.}

La relación de la publicidad con la forma oral es estrecha. Se ha dicho que solamente un juicio oral puede estar abierto en realidad al público. Pero, además de tratarse de una relación estrecha, resulta ser también una relación saludable. Por ejemplo, el sistema mejora en el control de sus distintos operadores: jueces, abogados e intervinientes son vigilados por el público. Además, este sistema hace que tienda a mejorar el interés de las personas por la administración de Justicia. Fomenta también la veracidad de las alegaciones de las partes y las declaraciones de los testigos, o al menos desalienta la actitud contraria, facilitada en un modelo que imparte Justicia sin publicidad.

La publicidad que se aseguraba en el proceso antiguo era la publicidad propia de los sistemas escritos, esto es, la publicidad del expediente. Bajo este esquema los terceros (el público) no eran considerados. En otras palabras, las dificultades provenían no de la ausencia de normas legales, sino de la imposibilidad de compaginar dominio de la escritura y publicidad. Esta situación cambia favorablemente con la LEC. que consagra la publicidad general de todas las actuaciones orales. Las actuaciones de prueba, las vistas y las comparecencias cuyo objeto sea oír a las partes antes de dictar una resolución, se practicarán en audiencia pública (artículo 138.1). La práctica de actos en audiencia pública significa que debe permitirse la asistencia de cualquier persona distinta de las partes, sus representantes o defensores, que deseen presenciarlos. Respecto a lo que liga con la práctica de las pruebas, el artículo 289.1 ratifica la necesidad de proceder en vista pública. Ello guarda conformidad con lo prescrito tanto en la Constitución (artículo 120.1) como en el artículo 232 de la Ley orgánica del Poder Judicial.

Con todo, lo permite la propia Carta fundamental y también la Ley orgánica del Poder Judicial previene la posibilidad de celebrar vistas o audiencias orales a puertas cerradas, es decir, con la sola presencia del Tribunal, secretario judicial, partes y asistentes de éstas. Las razones o intereses, verdaderos bienes jurídicos que el legislador desea proteger aún renunciando a la publicidad general, y que pueden justificar una decisión en este sentido son las que siguen: i) Cuando sea necesario para la protección del orden público o de la seguridad nacional en una sociedad democrática; ii) Cuando los intereses de los menores o la protección de la vida privada de las partes y de otros derechos y libertades lo exijan; y iii) En la medida en la que el Tribunal lo considere estrictamente necesario, cuando por la concurrencia de circunstancias especiales la publicidad pudiera perjudicar 
los intereses de la justicia. Estas excepciones coinciden en gran medida con aquellas que permite la normativa internacional ${ }^{72}$.

\section{Presencia e inmediación judicial en las vistas.}

La delegación de funciones fue la respuesta generalizada que la práctica forense otorgó a la normativa que la LEC. consagraba con relación a la presencia del juez, especialmente en lo relativo a la práctica de las pruebas. De esta forma, la figura del juez pasó a ocupar un segundo plano, siendo reemplazada por la del funcionario subalterno o un auxiliar de la jurisdicción que se hacía cargo de las distintas actuaciones y diligencias para las cuales la ley exigía la presencia judicial ${ }^{73}$. Esta irregular situación también cambia con la nueva normativa ${ }^{74}$. La inmediación es tomada en serio. Se reposiciona la figura del juez. La LEC. establece no sólo la regla procesal de la presencia judicial, sino también la inmediación judicial, previendo severas sanciones ante el incumplimiento (artículo 137).

Para varios, la esencia del proceso oral, una de las reglas procesales más relevantes y centrales que informan el sistema formal de la oralidad, para otros, precisamente uno de los más caros objetivos que debe conseguir la implementación de la forma oral en los juicios. Tanto así que se ha señalado que el valor de la oralidad consiste esencialmente en la inmediación, esto es, en aquella regla que permite utilizar en la valoración de las pruebas la observación directa e inmediata. Cualesquiera que sea el punto de vista que se adopte, mediante este concepto se alude a la existencia de un proceso cuyas distintas actuaciones se deben desarrollar ante el juez de la causa sin la interposición de elementos mediatizadores, donde el convencimiento del que falla sea extraído de la asistencia personal a la práctica de las pruebas, del contacto con las partes, con los testigos, con los peritos y con los objetos del juicio, evitando las referencias escritas ajenas.

La nueva regulación en este extremo se puede desglosar así: i) Los jueces y los magistrados miembros del Tribunal que esté conociendo de un asunto presenciarán las declaraciones de las partes y de los testigos, los careos, las exposiciones, explicaciones y respuestas que hayan de ofrecer los peritos, así como la crítica oral de su dictamen y cualquier otro acto de prueba que, conforme a lo prescrito por la LEC., deba llevarse a cabo

${ }^{72} \mathrm{Al}$ respecto véanse los artículos 14.1 del Pacto internacional de derechos civiles y políticos de 1966 y el art. 6.1 del Convenio para la protección de los derechos humanos y de las libertades fundamentales de 1950.

${ }^{73}$ Especialmente véase: Varela Castro, L., Inmediación judicial: Agonía de una fundamental garantía en Revista Justicia 1 (1987), pp. 95-101.

${ }^{74}$ También, por cierto, en la práctica, donde se observa un cumplimiento riguroso de la inmediación en los juicios y vistas de los procesos de la LEC. 
contradictoria y públicamente; ii) Las vistas y comparecencias que tengan por objeto oír a las partes antes de dictar una resolución se celebrarán siempre ante el juez o los magistrados integrantes del Tribunal que esté conociendo del asunto; y iii) La infracción de estas reglas determinará la nulidad de pleno derecho de las actuaciones realizadas sin la presencia judicial. A esta norma de general aplicación debe agregarse la contenida en el artículo 289.2 de específica aplicación para la práctica de la prueba en los procesos civiles: "Será inexcusable la presencia judicial en el interrogatorio de las partes y de testigos, en el reconocimiento de lugares, objetos o personas, en la reproducción de palabras, sonidos, imágenes y, en su caso, cifras y datos, asi como en las explicaciones, impugnaciones, rectificaciones o ampliaciones de los dictámenes periciales".

La inmediación entonces consiste en que sea el juez que presenció e intervino directamente en la práctica de la prueba el que dicte la sentencia. Es indispensable que coincida la persona que percibe la prueba con aquélla que va a dictar el fallo. El nuevo modelo, predominantemente oral, requiere y exige una dinámica diferente, en la cual la presencia e inmediación judicial cumplan un papel o rol mucho más relevante que bajo la LEC. de 1881.

\section{Unidad de acto y concentración procesal.}

La oralidad no solo se nutre con la regla de la inmediación judicial, también se vincula con la regla de la concentración procesal, al punto de haberse expresado por Chiovenda que: "decir oralidad es decir concentración". No en vano se le considera por algunos como la principal característica exterior del proceso oral y la que tiene mayor incidencia en las ventajas que se asocian a esta clase de juicios, por ejemplo, en lo que liga con la mayor brevedad de los pleitos ${ }^{75}$. La concentración procesal ca-

${ }^{75}$ Expresa Lorca Navarrete, A. M., Tratado de Derecho procesal civil. Parte general. El nuevo proceso civil (Madrid, Dykinson, 2000), p. 340: "La oralidad supone concentración. La concentración ejerce una importante influencia en orden a obtener un ejercicio funcional de la jurisdicción relativamente breve, pues en el dominado por la oralidad todas las cuestiones previas e incidentales -incidentes- se concentran en la vista, y/o juicio, sin que impidan la entrada en el fondo del asunto ni provoquen, una vez dentro de él, la sustanciación de incidentes”. VÁsquez Sotelo, J., La oralidad y escritura en el moderno proceso civil español y su influencia sobre la prueba, propone descartar la creencia de que un proceso oral es más rápido que uno escrito. En efecto, señala que cuando se defiende que el procedimiento debe estar guiado por la oralidad, vale decir, cuando se postula la superación de un sistema tan escrito no se hace -al menos prioritariamente- para obtener una resolución más rápida sino para lograr un proceso de superior calidad. Aunque, precisa, evidentemente, el ideal es que se logren las dos finalidades de una Justicia más rápida y de más calidad. Con 
racteriza el desarrollo de las vistas, y la LEC. prevé que en lo posible todas las pruebas se practiquen en unidad de acto (artículo 290) ${ }^{76}$. Se pretende que el juez, al momento de dictar su fallo, retenga en su memoria las alegaciones realizadas por las partes del pleito y el resultado de las distintas pruebas practicadas, sin necesidad de recurrir a los documentos.

La regla de la concentración, siendo relevante y central para el nuevo diseño, admite también excepciones. Ejemplo de ello encontramos en los artículos 290 y 429.4 que permiten la práctica de pruebas en momento distinto al juicio. Lo propio podemos decir respecto de las posibilidades de auxilio judicial para la práctica de pruebas (artículos 169 ss.).

\section{Resoluciones orales.}

El predominio de la oralidad y la concentración también se percibe tratándose de las resoluciones judiciales que no sean sentencias que se pronuncien durante la celebración de las vistas, audiencias o comparecencias. Efectivamente, con carácter general se establece que, excepto cuando la ley permita diferir su pronunciamiento, las resoluciones referidas deberán ser pronunciadas oralmente en el mismo acto oral, documentándose éste con expresión del fallo y motivación sucinta de aquellas resoluciones (artículo 210.1 y 3). Esta regla, insistimos, no se aplica tratándose de las sentencias que, como antes se señaló, se dictan por escrito, habiendo finalizado ya la audiencia ${ }^{77}$.

todo, agregamos nosotros, si bien es cierto que las dilaciones pueden producirse igual en un proceso oral que en uno escrito y que existen experiencias de consagración de procesos orales en donde los tiempos de la respuesta jurisdiccional no se han bajado, sino que incluso se han incrementado, las estadísticas de duración de los procesos con la nueva LEC. espańola no pueden calificarse precisamente de malas, todo lo contrario. Poco más de siete meses en promedio para la primera instancia, y cinco meses en promedio para la apelación. Todo esto con una excepción: el talón de Aquiles del nuevo sistema espańol está constituido por la casación, convertido en un verdadero problema desde que el Tribunal Supremo español resuelve procesos iniciados antes de la entrada en vigencia de la LEC. 1/2000.

${ }^{76} \mathrm{La}$ norma es de aplicación general, rige tanto para el juicio ordinario como para el juicio verbal. Por cierto, la concentración de la que hablamos también se puede constatar en la regulación de la audiencia previa al juicio, donde sin caer en extremos, se tiende a ella.

${ }^{77}$ Es una muestra de que en el nuevo modelo español no se ha operado con exceso de celo doctrinarista; más bien ha operado teniendo a la vista la mayor complejidad de los litigios civiles. En efecto, en el caso del juicio ordinario este plazo es de veinte días (superior al establecido por la LEC. derogada, pero inferior al que en la práctica se tomaban los jueces para fallar) respecto del cual en la Exposición de Motivos se dice que no se trata de un plazo que pueda considerarse, en sí mismo, excesivamente breve, pero sí razonable y de posible cumplimiento, porque es de tener en cuenta-se 


\section{Conveniencia de la forma escrita en la demanda.}

La forma escrita aparece como la más razonable, conveniente y segura de acuerdo al importante rol que tiene asignado la demanda, tanto como acto procesal iniciador del juicio civil como en la determinación y delimitación del contenido del mismo, que viene a determinar la suerte de una serie de instituciones procesales. Lo propio debe reconocerse respecto a la ampliación de la demanda.

Es un hecho también que en la actualidad la complejidad de los asuntos que se resuelven a través del juicio ordinario ha aumentado progresivamente. El correlato de la mayor complejidad de la sociedad ha sido justamente la mayor complejidad de los conflictos que surgen en su seno. Esta mayor complejidad no puede dejar de tener consecuencias en el proceso. Por ello, el legislador, al diseñar y configurar formalmente los distintos actos procesales del juicio debe tener a la vista esta realidad fáctica que hunde sus raíces en la realidad procesal. Es de recibo que el tratamiento de estas señaladas mayores complejidades son mejor abordadas a través de la forma escrita, la que permite el establecimiento certero y seguro del concreto objeto procesal, con todas las ventajas que esto acarrea en el adecuado desarrollo del debate procesal como en la correcta decisión del asunto litigioso.

Tratándose de la demanda y su eventual ampliación los “papeles” sirven. De hecho, permiten al actor exponer al Tribunal, sin prisas ni atolondramientos, la petición y causa de pedir que sirven para la configuración objetiva del objeto procesal. El escrito de demanda (y eventualmente su escrito de ampliación) permite que demandante y abogado planteen la concreta solicitud de tutela jurisdiccional con mayores grados de claridad y orden con lo que el planteamiento petitorio inicial tiene mejores posibilidades de servir a los intereses del proceso, en donde incluimos, por cierto, el legítimo interés del juez de la causa de contar con los elementos suficientes que le ayuden a conocer el asunto sobre el cual deberá dictar sentencia.

\section{dado. \\ 9. Conveniencia de la forma escrita prevista para la respuesta del deman-}

La forma que gobierna las alegaciones del demandado es la escritura, lo que se estima una decisión acertada. El juicio ordinario, no obstante los destacados esfuerzos de racionalización en sus trámites, continúa siendo

agrega- que la estructura nueva de procesos ordinarios comporta el que los jueces tengan ya un importante conocimiento de los asuntos y no hayan de estudiarlos o reestudiarlos al final, examinando una a una las diligencias de prueba llevadas a cabo por separado, así como las alegaciones iniciales de las partes y sus pretensiones, que, desde su admisión, frecuentemente no volvieron a considerar. 
el proceso mediante el cual deben resolverse asuntos de gran complejidad técnica. La LEC. rechaza las fórmulas simplistas que han pretendido convertir al proceso civil en algo que la misma realidad impide. Si la realidad es compleja, un diseño procesal que no previniera estas dificultades estaría destinado a la inutilidad o al colapso. Seguramente sería incapaz de servir, útilmente, de mecanismo de resolución de conflictos, constituyendo fuente de injusticias, procesales y materiales, producto de la inadecuación e insuficiencia del conocimiento adquirido por el juez que debe resolver el asunto. El juicio verbal está gobernado por el denominado "principio de celeridad" que imprime en él una característica distinta que justifica un diseño procesal más simple, más oralizado y concentrado. Lo que no impide, sin embargo, la existencia de varios problemas a la hora de aplicar la normativa que a su respecto se ha consagrado, justamente derivados de esta mayor simplicidad y concentración ${ }^{78}$.

El aseguramiento y concreción de las mejores posibilidades de ejercicio para las garantías de defensa del demandado (en esta fase del juicio) tiene mejor y más adecuada respuesta en la forma escrita, pues con similar tranquilidad a la que se asegura al demandante, podrá éste afrontar y decidir su estrategia defensiva, presentando las alegaciones que le permitan salir absuelto frente a la pretensión sostenida por el demandante (u obtener la condena del actor, si se trata de la demanda reconvencional).

\section{La audiencia previa al juicio y su importancia.}

La LEC. previene que la fase de alegaciones del juicio ordinario se divida en dos partes: la primera de ellas escrita e integrada por los actos procesales escritos recién aludidos, y la segunda oral, constituida por la que es la primera comparecencia del juicio ordinario, la denominada audiencia previa. De su regulación se encargan los artículos 414 a 430 LEC.

La opción por la oralidad en esta fase del proceso resulta ser muy importante para hacer realidad los cambios buscados por el legislador español. En estrecha coordinación con sus reglas conexas la oralidad permite desplegar los mejores frutos de esta audiencia previa al juicio. Bien ha precisado cierta doctrina. La oralidad propicia la concentración y hace indispensable la inmediación judicial, con lo que el tribunal pasa de una actitud pasiva a una actitud de protagonista en la dirección del proceso. La audiencia previa es un acto en donde el juez toma temprano contacto con el caso, situación que desde luego debe valorarse muy positivamente pues permite que las finalidades asignadas a ella puedan ser asumidas con mayor

\footnotetext{
${ }^{78}$ Nos remitimos a lo ya dicho.
} 
facilidad que si el juzgador se limitara a resolver en su despacho sobre la base de las presentaciones escritas que las partes le hicieran llegar.

Ya no se le puede considerar como un extraño y accesorio injerto oral que naufraga en medio de un proceso civil fundamentalmente escrito, como aconteció en relación con la comparecencia del juicio de menor cuantía regulado por la reformada LEC. de $1881^{79}$. La LEC. regula una audiencia previa fortalecida tanto en su contenido y regulación, como en su relación con el resto del procedimiento en el cual se inserta, también predominantemente oral. De hecho, se contempla a esta audiencia previa como una de las piezas claves del nuevo juicio ordinario prototipo.

El contenido asignado a la audiencia fuerza la presencia y participación activa de los jueces. A su turno, los preceptos regulatorios de la audiencia previa son indicativos de que se trata de un acto oral del proceso en que es determinante la inmediación. Se requiere y se reclama la inexcusable presencia del juzgador. Es el juez quien ha de conocer y resolver, la mayor parte de las veces en el mismo acto de la audiencia, las diversas cuestiones que en ella puedan suscitarse y es el juez quien debe dirigir la actividad de los litigantes.

No caben ni falseamientos ni delegaciones. Es la naturaleza y contenido de esta audiencia la que, por fin, logra imponer la presencia directa y frontal del juez, que más allá de su mera asistencia y presencia debe "tomar las riendas del asunto" (pero siempre dentro de los márgenes que permite la vigencia el principio dispositivo y la justicia rogada) desde un inicio, dejando atrás la imagen del juez lejano que aparentemente sólo se enteraba del litigio una vez que le correspondía fallarlo, al final de una larga serie de trámites. Se plantea un juez prudentemente protagonista de la audiencia que, con diligencia, dirija activamente el debate para sacar máximo provecho a las expectativas procesales del instituto.

La propia LEC. realiza un resumen de los contenidos de la audiencia previa al juicio en el artículo 414.1. En efecto, se señala que esta audiencia se llevará a cabo para intentar un acuerdo o transacción de las partes que

${ }^{79}$ Pese a la buena voluntad del legislador, al poco tiempo de vigencia de la reforma legal, el sistema fracasó, en gran medida por la desafortunada solución implantada en punto a la resolución de las cuestiones procesales, las que siguieron quedando diferidas para la sentencia definitiva, pero también porque no se crearon las condiciones ni personales ni materiales imprescindibles para que el sistema instaurado pudiera aplicarse efectivamente. La comparecencia no logró superar las dificultades de la incorporación de mayores grados de oralidad en un proceso eminentemente escrito $y$, de ahí, que la misma fuera en muchos casos falseada y sustituida por una serie de escritos. No pasó de ser una bienintencionada idea que terminó naufragando por la inexistencia de un modelo que evidenció su escasa utilidad práctica. 
ponga fin al proceso, examinar las cuestiones procesales que pudieran obstar a la prosecución de éste y a su terminación mediante sentencia sobre su objeto, fijar con precisión dicho objeto y los extremos, de hecho o de Derecho, sobre los que exista controversia entre las partes y, en su caso, proponer y admitir la prueba.

\section{La audiencia de juicio y el rescate de la actividad probatoria.}

La más importante revolución introducida por la LEC. viene dada por la regulación del acto del juicio como audiencia oral principal del proceso civil, y en torno a la cual deben necesariamente girar todos los esfuerzos que se desplieguen en el resto de las actuaciones procesales, incluidos, los realizados durante la audiencia previa al juicio recién señalada. Es en el nuevo acto del juicio donde debe buscarse la función principal de la oralidad.

La idea central de este cambio se concreta en torno a la consagración de una audiencia pública, oral, y concentrada, en la que las pruebas (con mayor rigor, la mayoría de las pruebas) son practicadas ante el juez que resolverá el caso. El cambio apunta al concreto diseño formal del sistema probatorio, que reemplaza a un modelo agotado y ya anticuado a la luz de las regulaciones que presentan desde hace ya años las legislaciones de la casi totalidad de países europeo.

Tras la audiencia previa se contempla, a modo de cierre, una audiencia oral y pública en donde en presencia efectiva del juez y de la manera más concentradamente posible se verifique la práctica de las pruebas. El legislador logra poner al día a Espańa en asuntos que comenzaron a evolucionar en esta dirección ya en el siglo XIX. El atraso provocado por los amarres formales de la escritura que gobernaba la prueba puede calificarse de monumental.

En esta audiencia se radica, tratándose del juicio ordinario, la piedra angular del cambio formal que se introduce en la LEC., consagrando una nueva manera de comprender el diseño del proceso y una de sus más decisivas actividades. Gracias a la apuesta legislativa por este modelo, concretamente por esta audiencia, y a su diseño elaborado sobre la forma oral, a la inmediación judicial preceptiva y real y a la mayor concentración probatoria posible, se produce en el proceso civil la revalorización de una actividad procesal maltrecha en el régimen anterior.

Escritura, dispersión en la práctica de las pruebas y delegación fueron el tradicional contexto formal para los procedimientos probatorios. En efecto, el modelo escrito no incentivó la presencia del juez en la práctica probatoria, lo contrario en realidad, facilitó la delegación en funcionarios de la Secretaría de tareas que por Ley sólo correspondían al juez. Se instaló en 
el juez español un sentimiento de inutilidad ${ }^{80}$ respecto a la inmediación, la práctica de pruebas careció de concentración y tuvo lugar en un momento procesal muy distante de aquél en que se pronunciaba la sentencia. La escritura gobernó la prueba: ni la contestación de palabra de la parte (en la absolución de posiciones) o la del testigo logra alterar la conclusión de la naturaleza profundamente escrita de los procedimientos probatorios, encuadrado en una serie de actos rigurosamente escritos que eran los que mandaban: El pliego de posiciones y el interrogatorio de preguntas y repreguntas. De la escritura entonces, no se llegaron a salvar ni las pruebas orales por excelencia, afectadas por un claro encorsetamiento formal.

Para superar estos problemas se consagra una actuación verdaderamente oral, pública, única y concentrada, con jueces, partes y abogados efectivamente visibles, presentes y activos, en contacto directo y frontal, donde contradictoriamente se procede a la práctica de las pruebas propuestas y admitidas.

\section{Apertura de los medios de prueba.}

La LEC., asumiendo la responsabilidad de la tarea de ser consecuente con la importancia que posee la actividad probatoria, y en adecuada consonancia con el diseńo predominantemente oral establecido, recoge una apertura legal de los medios de prueba, cerrando la puerta a los formalismos en la interpretación de la regulación procesal de los medios de prueba $^{81}$. De esta manera, la LEC. consigue alinearse con los postulados de la doctrina procesal, despejando así uno de los ripios formalistas más caracterizantes del modelo derogado. La "Exposición de motivos" ya destaca la apertura legal a la realidad de cuanto pudiera resultar conducente para fundar un juicio de certeza sobre las alegaciones fácticas, apertura que se estima incompatible con la idea de un número determinado y cerrado de medios de prueba. Asimismo, y con la finalidad de evitar los problemas evidenciados durante la vigencia de la Ley procesal derogada, se estima obligado el reconocimiento expreso de los instrumentos que permiten recoger y reproducir palabras, sonidos e imágenes o datos, cifras y operaciones matemáticas, sin necesidad de forzar la noción de prueba

${ }^{80}$ Ya tempranamente, según lo reflejan los comentarios realizados desde la mejor doctrina. Véase: Prieto Castro, L., Precisiones sobre la escritura y la oralidad en el Derecho Procesal español, en El Mismo, Estudios y comentarios para la teoría y práctica procesal civil (Madrid, Reus, 1950), pp. 75 ss.

${ }^{81}$ Incompatibles con la constitucionalización del derecho a la prueba, que impone -entre otras cosas- que la interpretación de las normas relativa a la admisión de los medios de prueba se oriente siempre hacia la efectividad del derecho de las partes a probar sus aseveraciones fácticas que son la base de sus pretensiones y defensas. 
documental para incluir en ella lo que se aporte al proceso con fines de la fijación de la certeza de hechos, que no sea subsumible en las nociones de los restantes medios de prueba.

\section{Una práctica probatoria renovada.}

La oralidad, la concentración, la inmediación judicial verdadera y la publicidad general toman la palabra para "rescatar" la fase más importante del proceso. Es en razón de los cambios implementados en la fase probatoria que el nuevo proceso civil español verdaderamente recoge un modelo formal oral, donde la acreditación del material fáctico aportado se produce oral y concentradamente, con la inmediación efectiva del juez y con general publicidad.

\section{La oralidad.}

La oralidad se instala efectivamente en la actividad de la prueba. Este desarrollo oral queda en especial evidencia tratándose de la práctica de las pruebas personales, donde la intervención en el proceso se realiza, por regla general, sin recurrir a la escritura. En efecto, tanto en el interrogatorio de las partes y testigos, como en la prueba de peritos (en el caso que deban exponer su informe y someterse a examen contradictorio de las partes) la opción del legislador está representada por la oralidad del diálogo. Es oral la forma de expresión de las partes, del juez y de los sujetos de prueba en los medios personales. Las ventajas de la forma oral en el campo de la actividad probatoria no pueden negarse. A su través, el proceso se libera de una de las peores lacras derivadas del carácter totalmente escrito del procedimiento recogido en la normativa anterior, el excesivo y en gran medida innecesario formalismo, que atentó, por ejemplo, contra de la eficacia de los interrogatorios sujetos a unos pliegos rígidos, añadidamente cerrados, y rara vez ampliados por la crónica inasistencia judicial. La oralidad que ahora se logra imponer constituye la evidente opción del legislador por las ventajas y posibilidades que viene a aportar la mayor flexibilidad y espontaneidad en el diálogo y procedimiento probatorio.

\section{La inmediación judicial.}

Su "debut", siguiendo la idea antes señalada, se verifica en el terreno de la realidad aplicativa de las distintas normas que la consagran. La inmediación judicial, en cuyas notables ventajas coincide toda la doctrina, aparece muy fortalecida gracias la nueva estructura procesal oral y concentrada. Se puede decir que esta estructura formal ha producido el milagro de una práctica de la prueba con efectiva presencia y participación del juez. Se impone el contacto e intervención directos e inmediatos del juez respecto 
a la actividad probatoria como una medida básica para garantizar la justicia y acierto de la actividad jurisdiccional decisoria, todo ello en congruencia con el sistema de valoración probatoria libre que se consolida con carácter general. Claramente, la LEC. potencia la figura del juez, imponiendo la cercanía entre el juez y el proceso, abandonando el paradigma del juez sentenciador "invisible", potenciamiento que se refuerza al acercar la práctica probatoria y el momento de la emisión de la sentencia.

\section{Concentración probatoria.}

Junto a la oralidad y la inmediación judicial real en el diálogo probatorio, la opción formal de la LEC. viene dada por la concentración de la actividad probatoria en un único acto (aunque conste de varias sesiones) y en la sede del Tribunal, que se plantea como la solución más razonable frente a la tradicional y perjudicial práctica dispersa de pruebas del anterior modelo.

Con su previsión se pretende que las actuaciones probatorias orales verificadas en el acto del juicio, su desarrollo y resultados, permanezcan en la memoria del juez a la hora de dictar sentencia, cuestión que se vería muy dificultada o imposibilitada si junto con la regla de la oralidad no se hubiese recogido también la exigencia de concentración en la práctica de las pruebas. Favorece y posibilita también la inmediación judicial efectiva y real.

\section{ROL DE LOS SUJETOS PROCESALES, EN ESPECIAL LA RELACIÓN DEL JUEZ Y LA PRUEBA}

\section{En el Derecho probatorio alemán.}

El rol de las partes y del juez dentro en el proceso civil alemán se manifiesta en la distribución de las responsabilidades tanto para el impulso procesal como para el aporte de las alegaciones y del material probatorio. Su concreción se efectúa en la audiencia oral como regla.

El centro de rol protagónico activo del juez lo establece el $\$ 139$ ZPO. que contiene una serie de deberes y facultades reconocidos aquel. Igualmente se introduce la posibilidad de requerir la presentación de documentos u objetos para su inspección a pedido de parte o de oficio.

Finalmente las partes y terceros tienen un deber de veracidad y esclarecimiento cuya extensión es discutida dogmática y jurisprudencialmente.

a) Deber de discusión. El $\$ 139$ ZPO. obliga al tribunal en colaboración con las partes, a esclarecer la controversia para poder decidirla. Este deber, que pesa en cabeza del juez, es necesario en tanto y en cuanto las partes y con las partes puedan discutirse las cuestiones de hecho y de 
derecho ${ }^{82}$ Los límites de la litis fijan el ámbito de ejercicio de este deber, así el Tribunal Constitucional Federal (BVerfGE.) se pronunció claramente en favor de la tutela del derecho a ser oído y del derecho de defensa sobre la base de esta disposición precisamente en su aplicación extralimitada ${ }^{83}$.

b) Deber de instrucción y de interrogación.

Existiendo dudas sobre los hechos y derecho debatidos, el tribunal debe interrogar o indicar a las partes para arribar a un mejor y más rápido esclarecimiento. El Tribunal Constitucional Federal considera contrario a la Ley Fundamental la omisión de dicho deber ${ }^{84}$.

c) Deber de esclarecimiento y función saneadora del juez. La claridad del contenido y la transparencia (sin vicios) por la cual se arriba a una decisión judicial sustentan el $\$ 139$ ZPO. La oralidad como vehículo $\mathrm{y}$ medio persigue que el debate probatorio permita a las partes y al tribunal -de manera clara y accesible-comprender a cabalidad el porqué y el cómo de una decisión. Son pertinentes al respecto las sentencias de tribunales de Colonia de 1969 y $1974,{ }^{85}$ y del tribunal de München de $1997 .{ }^{86} \mathrm{El} \mathrm{límite}$ de esta atribución está dado por la necesidad de esclarecer cuestiones de derecho o de hecho que pudieran obstaculizar razonablemente la validez y/o calidad de una sentencia ${ }^{87}$, no pudiendo ejercerse de una manera arbitraria que conduzca a perjudicar la posición de una de las partes ${ }^{88}$.

d) Deberes de documentación y registro del proceso. El apartado cuarto del $\$ 139$ ZPO. impone los deberes de documentación, registro y protocolización de los actos procesales vinculado ello con la publicidad del expediente. Todas las indicaciones, aclaraciones y advertencias que realice el juez deben ser debidamente protocolizadas o tomadas en el expediente de la manera adecuada para ello. Así el ejercicio de los deberes y

${ }^{82}$ Rensen, H., Die richterliche Hinweispflicht (Bielefeld, 2002), pp. 159 ss.

${ }^{83}$ BVerfGE, 84, p. 190: "El tribunal debe ejercer un debido control dentro del proceso, en relación con las afirmaciones de las partes, indicando a estas debidamente lo correspondiente a las cuestiones de hecho y de derecho discutidas".

${ }^{84}$ Así es, por ejemplo, en caso de argumentaciones o consideraciones que no sean sostenibles y en las que el tribunal debe ejercer su deber de pregunta e información. Ello fue considerado por el Tribunal Constitucional Federal como contrario al artículo 3, apartado $1^{\circ}$ de la Ley Fundamental, BVerfG, en Neue juristische Wochenschrift (1976), p. 1391; y en Monatsschrift für Deutsches Recht (1976), p. 820.

${ }^{85}$ OLG Köln, en Das juristische Büro (1969), p. 645; y OLG Köln (1974), p. 478.

${ }^{86}$ OLG München, en Neue juristische Wochenschrift (1997): "Rechtsprechungs-Report", p. 944.

${ }^{87}$ STürner, R., Die richterliche Aufklärung im Zivilprozeß (Tübingen, 1982), passim, esp. pp. 1-15.

${ }^{88}$ SCHNEIDER, cit. (n.64), No 90. 
facultades antes mencionados son registrados en el expediente y solamente pueden ser impugnados por demanda de falsedad. ${ }^{89}$

e) Presentación de documentos y objetos a requerimiento judicial. Con la nueva redacción (reforma 2002) del $\$ 142$ apartado $1^{\circ}$ y $\$ 144$ ZPO. el tribunal puede inmediata y directamente ordenar a un tercero o parte la presentación de documentos o determinados objetos de oficio o a petición de parte, para que los presente en tanto y en cuanto estos se vinculen con lo solicitado y aportado en relación con el proceso. De acuerdo con la nueva regulación, puede obligarse incluso al tercero cuando la parte que sostiene la existencia del documento no sea la titular de un derecho material para su restitución o presentación. ${ }^{90}$

f) Rol de las partes y responsabilidad compartida para el esclarecimiento de los hechos. Las partes tienen imperativos que están detallados en el $\$ 138^{91}$. Una posición se inclina por el mejor posible acceso a la verdad material sobre los pocos específicos intereses de libertad de los intervinientes procesales. Existiría así un deber básico de esclarecimiento procesal ${ }^{92}$. Otra posición no acepta la existencia de dicho deber, sino solo casos reconocidos por la propia jurisprudencia que reconoce como excepciones al nemo tenetur contra se accusare ${ }^{93}$.

${ }^{89} \mathrm{La}$ escrituración cualquiera sea el soporte persigue el control mediato por la publicidad de los actos de las partes y del tribunal. Ver Stein - Jonas - Leipold, ZPOKommentar, $\$ 278$, N o 53; STEIN - JonaS - Roth, ZPO-Kommentar, $\$ 160$, № 3 .

${ }^{90}$ Katzenmeier, Ch., Aufklärungs-/ Mitwirkungspflicht der nicht beweisbelasteten Partei im Zivilprozeß, en Juristenzeitung (2002), p. 538-540. Para un mayor tratamiento del tema ver DrencKhaHn, C., Urkundsvorlagepflichten im Zivilprozeß und im arbeitsgerichtlichen Verfahren nach der ZPO-Reform unter besonderer Berücksichtigung der Neufassung des \$ 142 ZPO (Frankfurt a. M., 2007), passim; Lang, S., Die Urkundenvorlagepflichten der Gegenpartei gemäß \$ 142 Abs. 1 Satz 1 ZPO (Frankfurt a. M. - Köln, 2007), passim.

${ }^{91} \$ 138:$ "Deber de declaración sobre hechos; deber de decir la verdad. 1) Las partes deben hacer sus declaraciones sobre cuestiones de hecho en forma completa y adecuada a la verdad. 2) Cada parte debe declarar sobre las alegaciones de hecho de su contraparte. 3) Los hechos que no sean discutidos en forma expresa deben considerarse como admitidos, cuando no pueda inferirse la intención de discutirlos de las declaraciones que efectúen las partes". En detalle, Peter, Münchener Kommentar, cit., $\$ 138$, No 1-17, 27-28, comp. con la edición actual del MünchKomm (2008) en el comentario al parágrafo efectuado por Wagner.

${ }^{92}$ Véase: Stürner, R., Die Aufklärungspflicht der Parteien des Zivilprozeßes (Tübingen, 1976), passim, esp. p. 29 ss., p. 85; Grunsky, W., Zivilprozeßrecht (12a edición, 2006), No 43, p. 31, quien sigue a F. BAur, Zivilprozeßrecht (6a edición, 1989); Katzenmeier, cit. (n. 90), pp. 533 ss.

${ }^{93}$ Rosenberg - Schwab - Gottwald, cit. (n. 6), \$ 108 III 2, p. 740 ss.; PrütTING, H., Gegenwartsprobleme der Beweislast (München, 1983), p. 137 ss.; Arens, P., 


\section{En el Derecho probatorio español.}

En punto a dilucidar esta cuestión, lo primero es señalar que el modelo procesal civil español se construye sobre el denominado principio de la justicia rogada (artículo 216), el que bien se ha destacado guarda una sabiduría basada en la experiencia acumulada durante mucho tiempo: "Son las partes procesales las que, además de la carga de alegar los hechos, desempeñan el papel decisivo en lo que su determinación o fijación como ciertos a los efectos del proceso" 94 .

La "Exposición de Motivos" es clara en este sentido. De allí que no se entienda razonable que al órgano jurisdiccional le incumba investigar y comprobar la veracidad de los hechos alegados como configuradores de un caso. Es a quien cree necesitar tutela a quien se atribuyen las cargas de pedirla, determinarla con suficiente precisión, alegar y probar los hechos $\mathrm{y}$ aducir los fundamentos jurídicos correspondientes a las pretensiones de aquella tutela. Con todo, prevé el legislador español la actuación activa del juez en distintos momentos del proceso.

a) Actuaciones de la audiencia previa que persiguen determinar con exactitud el objeto de la controversia. Uno de los objetivos de la audiencia previa está en la determinación con la mayor exactitud posible del objeto de la controversia. En esta tarea, la LEC. prevé que el juez tenga un papel especialmente destacado (favorecido por la oralidad), reflejo del papel activo que se espera del juez. Se dispone en el artículo 426.6 que el tribunal podrá requerir a las partes para que realicen las aclaraciones o precisiones necesarias respecto de los hechos y argumentos contenidos en sus escritos de demanda o contestación. Se acompaña esta facultad de una advertencia a las partes: Si las aclaraciones o precisiones requeridas por el juez no se efectuaren, el Tribunal les advertirá de que puede tenerlos por conformes con relación a los hechos y argumentos aducidos de contrario.

El objetivo perseguido es que queden claramente configurados los hechos y "argumentos" de cada una de las partes. La ley habla del requerimiento por parte del juez de precisiones "necesarias". La cuestión no resulta nada sencilla en la práctica, especialmente teniendo a la vista la necesidad de mantener la imparcialidad del juez.

Zur Aufklärungspflicht der nicht beweisbelasteten Partei im Zivilprozeß, en Zeitschrift für Zivilprozeß 96 (1983), pp. 1 ss.; véase igualmente: BGH Neue juristische Wochenschrift (1990), pp. 3151 ss., con crítica de STÜRNER, en Zeitschrift für Zivilprozeß 104 (1991), pp. 208 ss.

${ }^{94}$ De la Oliva Santos, Andrés - Díez-Picazo Giménez, I., Derecho Procesal civil. El proceso de declaración (3a edición, Madrid, Ed. Universitaria Ramón Areces, 2004), p. 277. 
En la misma dirección apuntada al inicio de este párrafo se anota lo dispuesto por el artículo 427.1 y 2: La toma de posición expresa de las partes respecto de los documentos, informes y dictámenes que hayan sido aportados por la contraria. En la audiencia, cada parte se pronunciará oralmente sobre los documentos aportados de contrario hasta ese momento, manifestando si los admite o impugna o reconoce o sí, en su caso, propone prueba acerca de su autenticidad. Asimismo, las partes, si fuere el caso, expresarán lo que convenga a su derecho respecto de los dictámenes periciales presentados, pudiendo admitirlos, contradecirlos o bien proponer que sean ampliados en los extremos que determinen. También se pronunciarán sobre los informes sobre hechos que se hubieran aportado inicialmente. Su importancia es clara y consustancial a la tarea de fijar con la mayor precisión posible el objeto de la controversia. Efectivamente, a su través se permite la entrada al juicio teniendo clara la base documental sobre la que el Tribunal deberá decidir.

Por último, realizadas las actividades señaladas, la audiencia continuará para que las partes o sus defensores, con el Tribunal, fijen los hechos sobre los que exista conformidad y disconformidad. Así lo dispone el artículo 428.1, que lo que hace es vincular la tarea de fijación y delimitación del objeto del juicio (thema decidendi) con la siguiente tarea que debe abordarse, cual es la proposición y admisión de la prueba, vale decir, la concreción del thema probandi.

b) La proposición de prueba. Otro de los contenidos de la audiencia dice relación con la proposición y admisión de la prueba. La llamada función probatoria de la audiencia previa. La doctrina ${ }^{95}$ ha destacado la escasa importancia que bajo la LEC. de 1881 se daba a la actividad probatoria, concebida como una serie de diligencias dispersas realizadas en un período de tiempo, frecuentemente complementadas por las denominadas diligencias para mejor proveer. La figura del juez poco enterado del contenido de los casos hasta el momento de dictar sentencia era la regla general. En este escenario, la proposición de prueba realizada por las partes se despachaba sin un conocimiento del asunto que permitiera al juez evaluar la pertinencia o impertinencia de la prueba propuesta. Por ello, hacer lugar a todas las pruebas propuestas por las partes fue la tónica, situación claramente fomentada por el carácter irrecurrible de la resolución que la admitía, ignorándose las graves consecuencias que ello acarreaba al proceso.

Con la nueva LEC. y de la mano de la oralidad que gobierna esta audiencia, su concentración y la inmediación judicial que se establece con

${ }^{95}$ Especialmente, véase: Díez-Picazo Giménez, I., cit. (n. 94), pp. 297 y 570. 
carácter preceptivo esto ha cambiado. Se debe valorar que la proposición y admisión de las pruebas se verifica dentro de la audiencia previa justo después de que los abogados de las partes hayan determinado con precisión el objeto de la controversia, lo que facilita mucho la proposición probatoria, pero sobre todo la decisión del juez sobre la admisión o inadmisión de las pruebas propuestas.

Se persigue que la prueba admitida sea la pertinente y la útil (artículo 429.2). La propia Constitución española solamente garantiza el derecho fundamental a utilizar los medios de prueba pertinentes (artículo 24.2 C.Esp.). La prueba propuesta que sea inútil e impertinente debe ser desechada e inadmitida por el juez.

c) La audiencia previa y el rol del juez en cuanto a la determinación de las pruebas que se rendirán. Además de la pertinencia, utilidad y legalidad señaladas, las pruebas propuestas por las partes deben ser suficientes para el esclarecimiento de los hechos controvertidos. No se trata de una exigencia que se imponga de modo expreso por el legislador, sin embargo, su existencia se desprende de la norma del artículo 429.1.II y III. Se incorpora por la ley a este respecto una regla específica, a través de la cual se encomienda al juez una tarea de control, advertencia o sugerencia probatoria frente a la insuficiencia probatoria del conjunto de la propuesta de las partes. Algo sin antecedentes en la LEC. derogada y sin encaje fácil en el modelo de la LEC., que por lo mismo ha generado polémica y dudas en torno a su aplicación.

En efecto, cuando el juez considere que las pruebas propuestas pudieran resultar insuficientes para el esclarecimiento de los hechos controvertidos lo pondrá de manifiesto a las partes. Indicará el hecho o hechos que, a su juicio, podrían verse afectados por una insuficiencia probatoria. Al efectuar esta manifestación, el Tribunal, ciñéndose a los elementos probatorios cuya existencia resulte de los autos, podrá señalar la prueba o pruebas cuya práctica considere conveniente a los efectos de superar la insuficiencia probatoria. Las partes, a la vista de lo manifestado por el juez, podrán completar o modificar sus proposiciones de prueba originales, también oralmente (artículo 429.1.II y III).

Se ha destacado que esta norma es producto de una solución de compromiso a la que se vio obligado el legislador para compensar la restricción de la iniciativa probatoria tras la supresión de las diligencias para mejor proveer y su sustitución por unas diligencias finales que, por regla, se deben adoptar a instancia de parte.

Los riesgos de prejuzgamiento y la consecuente afectación de la neutralidad e imparcialidad del juez se han denunciado por un sector de la doctrina. Si bien es cierto que antes de la práctica de la prueba en principio 
se ignora a quién puede beneficiar o perjudicar ${ }^{96}$, la manifestación judicial de los hechos que se podrían ver afectados por insuficiencia probatoria implica un juicio de valor que merma la imparcialidad del juez, en cuanto supone la indicación de hechos aducidos por una de las partes y no por la otra.

Ahora bien, los litigantes siguen conservando la disposición sobre la proposición de la prueba. El artículo 429.1 no libera a las partes de la carga de la alegación y de la prueba, ni transfiere la misma al juzgador. De hecho, aún ejerciendo el juez la obligación y facultad recogidas por la norma, no puede imponer su criterio a las partes, lo que deja en evidencia dónde sitúa el legislador la dirección final de la actuación: "Las partes podrán completar o modificar sus proposiciones de prueba a la vista de lo manifestado por el tribunal' (artículo 429.1.III). Los litigantes no quedan vinculados a lo manifestado por el tribunal, ni en lo relativo a la manifestación de insuficiencia probatoria, ni en el posible señalamiento de pruebas cuya práctica considere conveniente. No se consagra ningún deber de seguir la indicación del juez. Otra cosa distinta es el impacto que el señalamiento judicial produzca en los hechos en los abogados.

Lo que debe estar fuera de discusión es que si ninguna de las partes propone la prueba sugerida por el Tribunal, éste no puede acordarla de oficio, lo contrario iría en contra del principio de aportación de parte que gobierna el proceso civil. El artículo 429.1 no habilita en ningún caso al Tribunal a ordenar prueba de oficio en el proceso civil. Tan sólo le permite recomendar a las partes que modifiquen su proposición de prueba, ampliándola a otras que pueden resultar interesantes para acreditar los hechos controvertidos.

Además, será muy difícil para el juez manifestar que un hecho relevante para la decisión del juicio pueda adolecer de insuficiencia probatoria cuando aún no se ha practicado la prueba propuesta por las partes para acreditarlo. En este momento del proceso aún se desconoce el resultado de las pruebas propuestas y admitidas en orden a la acreditación de los hechos ${ }^{97}$. En los

\footnotetext{
${ }^{96}$ Picó I Junoy, J., La iniciativa probatoria del Juez civil y sus límites, en Revista del Poder Judicial 51 (1998), pp. 286-287.

${ }^{97}$ En este punto las voces críticas se escuchan desde prácticamente todos los sectores de la doctrina, inclusive de aquéllos más proclives a la introducción de facultades judiciales en materia de iniciativa procesal apoyados en la concepción socializadora o publicista del proceso civil. Se ha seńalado que, salvo en los supuestos claramente evidentes de insuficiencia probatoria, existe una gran dificultad a la que se enfrenta el Tribunal a la hora de formarse el juicio provisional acerca de la insuficiencia de las pruebas propuestas por las partes; le corresponde pronosticar, antes de su práctica, el resultado probatorio a que conducirá respecto de los hechos controvertidos aquella propuesta.
} 
hechos se le está pidiendo al juzgador una conducta adivinatoria. Por ello, en la práctica, la aplicación de la norma se ha reducido a supuestos de insuficiencia manifiesta y clara de pruebas que sin lugar a dudas son conducentes a un resultado concreto, o bien a casos de mero olvido en la proposición de las pruebas.

d) Rol del juez en la práctica de las pruebas. Más allá de la preceptiva presencia del juez en la audiencia de juicio, la LEC. contempla la participación de éste en la recepción de la prueba. En la prueba de interrogatorio de parte se prevé que el juez pueda interrogar a la parte con la finalidad de obtener aclaraciones y adiciones a las respuestas dadas a los interrogatorios formulados por las partes. Creemos que este rol que se ha asignado al juez es el que se corresponde con un proceso civil como el español, gobernado razonablemente desde la vigencia de los principios dispositivos y de aportación de partes. El juez no puede (lo tiene vedado) introducir nuevos hechos, tarea que corresponde a las partes, pues a ellas se atribuye, como hemos dicho en otro lugar, la determinación del objeto del proceso y del debate, y lo haría si las adiciones a las que se refiere el legislador no están referidas y ligadas a las respuestas dadas a preguntas ya formuladas por las partes. La LEC. repite esta fórmula tratándose de la prueba testimonial.

En la prueba pericial también se le reconoce al juez la facultad de actuación de oficio, y concretamente se le autoriza por la Ley para preguntar a los peritos y requerir de ellos explicaciones sobre lo que sea objeto del dictamen aportado, lo que es más que lo que se le autoriza a propósito de la prueba de interrogatorio de partes y testigos, y desde luego es más que lo que la LEC. de 1881. regulaba, que no permitía al juez solicitar explicaciones, limitando la intervención judicial únicamente a realizar al perito las observaciones que las partes o sus defensores solicitaran en el mismo acto de la declaración o ratificación de su dictamen.

e) El juez y las diligencias finales (sustitutivas de las diligencias para mejor proveer). Con la LEC. se deja atrás la interminable "trampa de papeles" propia de la estructura de la LEC. de 1881, la dispersión que le era consustancial y la frustrada efectividad del contacto directo entre el juzgador y las partes y sus medios de prueba, que "obligó" a que bajo los años de vigencia de la derogada ley muchos de los actos de prueba se debieran dejar para el final, ya terminado el juicio, ya citadas las partes para oír la sentencia, recurriendo a las medidas para mejor resolver. De allí que el plazo para dictar sentencia se convirtiera en muchos casos en el momento en que los jueces buscaban paliar las consecuencias de su ausencia en la práctica de las pruebas. Los jueces podían acordarlas de 
oficio, sin instancia de parte, significaban una verdadera puerta abierta a los poderes oficiosos del juez en la actividad probatoria.

La ley suprime las denominadas "diligencias para mejor proveer", sustituyéndolas por unas "diligencias finales", con presupuestos distintos de los de aquéllas. La supresión de las diligencias para mejor proveer es conveniente por cuanto refuerza la importancia del acto del juicio restringiendo la actividad previa a la sentencia a aquello que sea estrictamente necesario. Como diligencias finales sólo son admisibles las diligencias de pruebas, debidamente propuestas y admitidas, que no se hubieren podido practicar por causas que hayan sido ajenas a la parte que las hubiera interesado. La ley considera improcedente llevar a cabo nada de cuanto se hubiera podido proponer y no se hubiere propuesto, así como cualquier actividad del Tribunal que, con merma de la igualitaria contienda entre las partes, supla su falta de diligencia y cuidado.

f) El juez y la valoración de las pruebas. La opción del legislador español ha estado dirigida a consagrar un sistema de valoración de las pruebas lo más coherente posible con la nueva estructura oral, concentrada y propiciadora del contacto directo entre el juez, las partes y sus respectivos medios de prueba.

Se logra consolidar e intensificar el componente de valoración libre del sistema, de dificultosa existencia efectiva (real) durante el anterior régimen procesal escrito, disgregado y mediatizado, componente de libertad de valoración que pasa a predominar con mucha mayor claridad, y sobre todo, con mayor naturalidad, manteniéndose así el modelo procesal español (ahora sin las dificultades propias de la estructura formal del modelo derogado) dentro de lo que marca la ruta procesal del resto de los países occidentales.

Ha destacado la doctrina el estrechísimo vínculo entre las formas del procedimiento y la función de la prueba, incidiendo especialmente en el nexo entre la oralidad y la inmediación. Concretamente, la oralidad entendida como la "inmediación” en la relación entre el juzgador que debe dictar sentencia y los elementos de los cuales debe extraer su convicción (personas, objetos y lugares), como la condición indispensable para la actuación del principio de la libre convicción del juez en oposición al sistema de la prueba legal. El mismo juez que debe dictar la sentencia deberá escuchar las respuestas de las partes, las deposiciones de los testigos, las explicaciones de los peritos, examinará los objetos, visitará los lugares, entrando así en contacto inmediato con las fuentes de su convencimiento.

Se opta por el fortalecimiento de la valoración libre de las pruebas mediante la eliminación de algunas de las manifestaciones injustificadas del sistema de valoración legal con la actual regulación de los medios de 
prueba. En consecuencia, la valoración libre de las pruebas se fortalece en la LEC. tanto a través de la eliminación de las rigideces legales que aparecían como injustificadas incluso bajo la vigencia de la LEC. de 1881, claramente incompatibles con el modelo procesal instaurado, como mediante la asunción de un modelo formal que, a diferencia del derogado, facilita, da sentido, y hasta potencia la adecuada reflexión judicial valorativa a la luz de unas pruebas rendidas, por regla general, con presencia e intervención efectiva del juez.

\section{CONCLUSIONES}

De lo tratado pueden extraerse las siguientes conclusiones:

a) La oralidad ha sido y debe ser considerada central no solo desde el punto de vista externo del proceso para su celeridad y transparencia, sino además desde lo interno para el logro más coherente de la incorporación y apreciación de la prueba: el juez debe apreciar y valorar la prueba según los cánones de la sana crítica.

b) El principio de oralidad sumado a otros principios, en especial al de inmediación y concentración, tiene un gran número de ventajas comparativas para una eficiente tramitación procesal, como así también para un mayor sustento de la legitimidad y credibilidad de la sentencia.

c) La obligatoriedad de la audiencia oral destinada a la práctica concentrada de las pruebas implica que solo puede decidirse previa audiencia oral y sobre lo conocido en ella. Sólo aquello que fue objeto de la audiencia oral puede servir de fundamentación para la resolución que se pronuncien. Las peticiones probatorias y las alegaciones de las partes efectuadas en audiencia oral deben ser consideradas aceptándolas o rechazándolas en la sentencia definitiva.

d) La oralidad no excluye (ni debe excluir) la posibilidad de actuaciones escritas de las partes y del tribunal. La apología hacia una oralidad desbordada no encuentra eco ni en el sistema alemán ni español.

e) La audiencia oral principal debe prepararse. Existen alternativas en el modelo alemán, en donde puede prepararse en forma oral o escrita, si el tribunal lo ordena por considerarlo necesario. En el modelo español rige la audiencia preparatoria del juicio que si bien se aparta de la tendencia europea ha mostrado un muy buen funcionamiento incluso en litigios complejos y de importancia.

f) El rol del juez dentro del proceso civil oral es más activo. Se trata de un juez visible y presente, pero también más activo desde la perspectiva de su rol ante la prueba. Difieren los distintos modelos a la hora de concretar este rol, siendo más acentuado en Alemania (en donde se manifiesta en 
la distribución de las responsabilidades tanto para el impulso procesal como para el aporte de las alegaciones y del material probatorio), que en España en donde existe un sistema que es resultado de una solución de compromiso que mezcla la oficiosidad en la fase de proposición de prueba, con las limitaciones para la actuación oficiosa del juez tratándose de las nuevas diligencias finales.

[Recibido el 5 de enero y aceptado el 9 de marzo de 2009].

\section{BIBLIOGRAFÍA}

\section{Autores}

Alonso-Cuevillas Sayrol, J. (coord.), Instituciones del nuevo proceso civil. Comentarios sistemáticos a la Ley 1/2000 (Barcelona, Difusión Jurídica, 2000).

Arens, P., Mündlichkeitsprinzip und Prozeßbeschleunigung im Zivilprozeß (Berlin, 1971).

Arens, P., Zur Aufklärungspflicht der nicht beweisbelasteten Partei im Zivilprozeß, en Zeitschrift für Zivilprozess 96 (1983).

Baur, F., Wege Zu Einer Konzentration der mündliche Verhandlung (Berlin, 1966).

Benda, E. - Weber, A., Der Einfluß der Verfassung im Prozeßrecht, en Zeitschrift für Zivilprozeß 96 (1983).

Bender, R., Das Verfahren nach der Vereinfachungsnovelle und vor dem Familiengericht (München, 1977).

Chong-Hu, O., Der Prozessstoff der zweiten Intanz im Zivilprozess in der deutschen Gesetzgebungsgeschichte seit 1877 (Berlin, 2004).

Dagmar, U., Adolf Wach (1843-1926) und das liberale Zivilprozessrecht (Berlin, 2005).

De la Oliva Santos, A., Sobre la Ley 1/2000, de 7 de enero, de Enjuiciamiento Civil: criterios inspiradores e innovaciones principales, en Revista de los Tribunales de Justicia 2 (2000).

De la Oliva Santos, A. - Díez-Picazo, I. Derecho procesal civil (Madrid, 2005).

De la Oliva Santos, A. - Díez-Picazo Giménez, I. - Vegas Torres, J. - BanaCloche Palao, J., Comentarios a la Ley de Enjuiciamiento Civil (Madrid, Civitas, 2001).

Díez-Picazo Giménez, I. - Martínez-Simancas y Sánchez, J., Estudios sobre Derecho Procesal, Central Hispano (Madrid, 1996).

DrenCKHAHN, C., Urkundsvorlagepflichten im Zivilprozess und im arbeitsgerichtlichen Verfahren nach der ZPO-Reform unter besonderer Berücksichtigung der Neufassung des $\$ 142$ ZPO (Frankfurt am Main, 2007).

GotTwald, P., Simplified Civil Procedure in West Germany, en The American Journal of Comparative Law 31 (1983) 4.

Grunsky, W., Zivilprozessrecht (Tübingen, 2008).

Katzenmeier, Ch., Aufklärungs-Mitwirkungspflicht der nicht beweisbelasteten Partei im Zivilprozess, en Juristenzeitung (2002).

Kip, H.G. - Von Hippel, F., Das sogenannte Mündlichkeitsprinzip (Köln, 1952). 
Langbein, J., The German Advantage in Civil Procedure, en Chicago University Law Review 52 (1985).

Lange, M., Bezugnahme im Schriftsatz, en Neue juristische Wochenschrift (1989).

LeIPOLD, D., Zivilprozeßrecht und Ideologie, en Juristenzeitung (1982).

Lorca Navarrete, A. M., Tratado de Derecho procesal civil. Parte general. El nuevo proceso civil (Madrid, 2000).

Lepsius, S. - Wetzstein, T., Als die Welt in die Akten kam Prozeßschriftgut im europäischen Mittelalter Rechtsprechung (Frankfurt am Main, 2008), VIII.

LüKE, G., Münchener Kommentar zur Zivilprozeßordnung (Múnich, 2002).

Murray, P. - Stürner, R., German Civil Justice (North Caroline, 2004).

Peter, E., Münchener Kommentar zur Zivilprozessordnug, Aktualsierunsband ZPO Reform (München, 2002 / 2004).

Picó I Junoy, J., La iniciativa probatoria del Juez civil y sus límites, en Revista del Poder Judicial 51 (1998).

Prieto Castro, L., Estudios y comentarios para la teoría y práctica procesal civil (Madrid, Reus, 1950).

Prütting, H., Gegenwartsprobleme der Beweislast (München, 1983).

Prütting, H., Münchener Kommentar zur Zivilprozeßordnung (München, 2008), I.

Prütting, H. - Stickelbrock, B., Zwangsvollstreckungsrecht (Stuttgart, 2002).

Ramos Méndez, F. (dir.), Para un proceso civil eficaz (Bellaterra [Barcelona], Servicio de Publicaciones de la Universidad Autónoma de Barcelona, 1982).

Rauscher, T., Münchener Kommentar zur Zivilprozeßordnung (München, 2008), I.

Rensen, H., Die Richterliche Hinweispflicht (Bielefeld, 2002).

Rosenberg, L. - Schwab, K. H. - Gottwald, P., Zivilprozessrecht (München, 2004).

Schnellenbach, H., Grundsätze des gerichtlichen Verfahrens, en Juristische Arbeitsblätter (1995).

Schwaв, K.H. - Gotтwald, P., Verfassung und Zivilprozess (Bielefeld, 1984).

Stein, F. - Jonas, M., ZPO-Kommentar (Tübingen, 2008), IV.

Stürner, R., Die Aufklärungspflicht der Parteien des Zivilprozesses (Tübingen, 1976).

STÜRner, R.,Die richterliche Aufklärung im Zivilprozess (Tübingen, 1982).

STÜrner, R., Prinzipien der Einzelzwangsvollstreckung, en Zeitschrift für Zivilprozess 99 (1986).

Varela Castro, L., Inmediación judicial: agonía de una fundamental garantía, en Revista Justicia 1 (1987).

Vollkommer, M., Zivilprozessordnung (Köln, 2007).

WaCH, A., Grundfragen und Reform des Zivilprozesses (Berlin, 1914).

WAGner, C., Münchener Kommentar zur Zivilprozeßordnung (München, 2008)

Walter, G., Freie Beweiswürdigung (Tübingen, 1979).

2. Jurisprudencia

BGH NJW, Neue juristische Wochenschrift, 1990.

BGH NJW, Neue juristische Wochenschrift, 1997.

BGH NJW, Neue juristische Wochenschrift, 1999.

BGH NJW, Neue juristische Wochenschrift, 2002.

BverfG., en Neue juristische Wochenschrift, 1976

BverfG., 1 BvR 620/07 del 19.12.2007, No 1 - 62. 
BverfG., 2 BvR 779/04 del 19.10.2004, No 1 - 40.

BverfG. en Juristenzeitung (1983).

CGPJ. Informe sobre la incidencia de la aplicación de la nueva Ley de Enjuiciamiento Civil, en Revista Tribunales de Justicia 12 (2001).

Monatsschrift für Deutsches Recht (1976).

OLG Colonia, en Das juristische Büro (1969).

OLG Colonia, 1974.

OLG München, en Rechtsprechungs-Report der NJW (1997).

Providencia del 10 de enero 2006 - 1 StR 527/05, en Neue juristische Wochenschrift (2006).

BGH Resolución del 6.10.2008, en NotarZ 6/08 